\title{
Structural Estimation of Search Intensity: Do non-employed workers search hard enough?*
}

\author{
Pieter A. Gautier ${ }^{\dagger}$ \\ Vrije Universiteit Amsterdam, Tinbergen Institute, CEPR \\ José Luis Moraga-González \\ University of Groningen \\ Ronald P. Wolthoff ${ }^{\S}$ \\ Vrije Universiteit Amsterdam, Tinbergen Institute \\ Preliminary version \\ 18 May 2007
}

\begin{abstract}
The speed at which unemployed workers find jobs depends on their search intensity. Most of the literature defines search intensity as a scalar that influences the arrival rate of job offers. In this paper we treat it explicitly as the number of job applications that workers send out in a given period. This number of applications and the wage distribution are simultaneously determined. We structurally estimate the search cost distribution, the implied matching probabilities, the productivity of a match, and the flow value of non-labor market time within a segment. These estimates are then used to derive the socially optimal distribution of search intensities. We find that, from a social point of view, too little workers participate and that the unemployed workers search too much. The low participation rate reflects a standard hold-up problem and the excess number of applications per worker is due to rent seeking behavior. Most welfare gains can be realized by a combination of opening more vacancies and increasing participation. If they are set optimally, output could be about $15 \%$ higher. A positive modest binding minimum wage or UI benefits conditional on applying at least once, increases participation, decreases rent seeking and decreases entry. The total welfare effects of those instruments are positive as long as they are set not too high.
\end{abstract}

Keywords: job search, search costs, labor market frictions, wage dispersion, welfare, structural estimation JEL codes: J64, J31, J21, E24, C14

\footnotetext{
${ }^{*}$ We are grateful for comments received from Jaap Abbring, Gerard van den Berg, Charles Bos, Gregory Jolivet, Bas van der Klaauw, and Matthijs Wildenbeest. We also thank participants of the Third Meeting of the Microdata RTN at CEMFI, Madrid, the NAKE Research Day and seminar participants at the Tinbergen Institute Amsterdam for useful comments. Gautier acknowledges financial support from NWO through a VIDI grant.

$\dagger^{\dagger}$ Department of Economics, Vrije Universiteit Amsterdam, De Boelelaan 1105, 1081 HV Amsterdam, pgautier@feweb.vu.nl.

¥Department of Economics, University of Groningen, PO Box 800, 9700 AV Groningen, j.l.moraga.gonzalez@rug.nl.

$\S$ Department of Economics, Vrije Universiteit Amsterdam, De Boelelaan 1105, 1081 HV Amsterdam, wolthoff@tinbergen.nl.
} 


\section{Introduction}

Many active labor market policies aim at increasing the search intensity of non-employed workers. Examples include cuts in unemployment benefits for workers who do not actively search (unemployment sanctions), see Abbring, Van den Berg and Van Ours (2005), helping long term unemployed workers to write application letters (counselling and monitoring), see Van den Berg and Van der Klaauw (2006), or subsidizing child care in order to increase the number of actively searching workers, see Heckman (1974) and Graham and Beller (1989). The evaluation of policy programs of this kind is not easy because search intensity is difficult to measure directly. In this paper we present a structural approach to evaluate such public policies.

Since search intensity is the policy parameter of interest we propose a model where search intensity is explicitly modelled as the number of job applications workers send out per period. Specifically, we assume that workers are heterogeneous with respect to the cost they incur per job application. When looking for a job each worker chooses the number of job applications that maximizes expected lifetime utility so the incremental benefits (higher expected present value of income and higher employment probability) equal the marginal costs. Each application has a fixed probability to be accepted that follows from the structure of the model (but we allow this probability to vary over worker segments). Firms post wages which are observed by the workers after they get offers. As in Gautier and Moraga-González (2004), who consider a version of this model with identical workers, wages and the number of applications are jointly determined in a simultaneous-moves game. For the usual reasons as explained in Burdett and Judd (1983) and Burdett and Mortensen (1998), firms play mixed strategies and offer wages from a continuous wage offer distribution.

The kinds of policies we mentioned above can be interpreted in this framework as aiming to change the shape of the search cost distribution. For example, one goal of subsidizing child care is to reduce the fraction of the labor force that does not search at all, while counselling unemployed workers is likely to increase the mean number of job applications. We believe that it is very important to evaluate those policies in an equilibrium setting where both the wage distribution and the distribution of the number of applications that a worker sends out are endogenous. Wage or UI policies will also affect search intensity while policies that affect search intensity will also affect the wage distribution, so keeping one of them fixed will make the model unsuitable for studying policy interventions. We also believe that it is important to model the deviations

from an Arrow-Debreu world at the deepest possible level rather than in an ad hoc way in order to isolate the primitive parameters.

To our knowledge, this is the first paper that estimates an endogenous matching process rather than assuming some exogenous specification for a matching function or a job offer arrival rate. As in Albrecht, Gautier and Vroman (2006), the aggregate matching function is determined by the interplay between two coordination frictions: (i) workers do not know where other workers apply to and (ii) firms do not know where other firms apply to. We extend this matching function by allowing for worker heterogeneity in terms of search cost. In our model, the primitive parameters are not the job-offer-arrival rate or the elasticities of an exogenous matching function but points of the search cost distribution. To illustrate the difference, 
consider the effect of increasing the minimum wage which makes search on average more attractive. In our model, some people will now apply to one job rather than to zero jobs, some will apply to two jobs instead of one while others who applied to many jobs will now apply to fewer jobs because the wage distribution becomes more compressed. All of this will affect the aggregate matching rate. Consequently, the matching rate, the job offer arrival rate and the wage distribution are not policy invariant.

We estimate the model by maximum likelihood. ${ }^{1}$ Our model implies a relation between the accepted wage distribution and the wage offer distribution (which we do not directly observe). Then, we use this wage offer distribution together with information on the employment inflow rate to estimate the search cost distribution where we use information from non-participation data to estimate the fraction of workers who do not search at all. Given her search cost, a worker chooses the optimal number of applications, taking into account that more applications increase the match probability and the expected wage. We use data on labor market tightness to estimate the job-offer-acceptance probability according to our endogenous matching function. This implies a value of the job acceptance probability that is increasing in labor market tightness and which is non-monotonic in the average number of applications.

We also derive the worker's reservation wage in each segment, which depends on the flow value of nonlabor market time (i.e. home production and UI benefits) and search-cost and wage distributions. Recently, Gautier and Teulings (2006) and Hornstein, Krusell and Violante (2006) argued that many search models cannot explain why reservation wages are substantially lower than the average or maximum wage, while at the same time unemployment or unemployment duration is low. In our model, unemployed workers who have low search cost today realize that they can have high search cost tomorrow. Therefore, they are willing to accept a low starting wages even though they have a large probability to receive one or more offers today.

In order to design optimal labor force participation and search intensity policies we must take into account general equilibrium and congestion effects. Without a suitable framework there is no way we can tell whether we should stimulate search intensity for all workers, only for particular groups or not at all. Too often it is just assumed that search intensity is too low without making explicit why. In our framework we can calculate, for a given search cost distribution, the socially desired distribution of applications and compare it with our estimates. It turns out that in the decentralized market equilibrium, workers send on average too many applications. There are two reasons for this. First, workers with very low search cost search too much relative to the social optimum because they do not internalize the fact that sending more applications increases the probability that multiple firms consider the same candidate. Second, search is partly a rentseeking activity: more applications increase the expected maximum wage offer. We show that the market equilibrium outcome is about $15 \%$ below the constraint planner's outcome. Since the planner increases participation, he also wants to increase the number of firms. However, given the optimal search strategies of the workers, entry would be excessively large in the market because firms basically have monopsony

\footnotetext{
${ }^{1}$ The estimation method is similar to that in the static consumer search model of Moraga-González and Wildenbeest (2006). Their model however is not directly applicable to the labor market since it does not capture the standard market frictions due to rationing.
} 
power. Interestingly, the introduction of a binding minimum wage can be desirable for 3 reasons: (i) it increases participation because the expected wage increases, (ii) it decreases rent seeking behavior, because it compresses the wage distribution and (iii) it also reduces entry which in some cases can be desirable. We model UI benefits to be conditional on searching at least once (as is the case in many OECD countries). We argue that the advantage of this is that it increases the marginal benefits of sending one application rather than zero by a lot, but at the same time it does not give additional incentives to search more often, which keeps the negative congestion effects low. UI benefits therefore also increase participation without increasing rent seeking behavior. A final and important lesson of our analysis is that increasing participation or stimulating vacancy creation in isolation have very small welfare effects: the large welfare gains come from the interaction of both. It can therefore be restrictive to evaluate separate labor market policies in isolation as is commonly done.

This paper is organized as follows. Section 2 describes the theoretical model and section 3 shows how it can be estimated by maximum likelihood. Section 4 discusses our data and in section 5 we present our estimation results and discuss efficiency. Section 6 discusses related literature and section 7 concludes.

\section{Model}

\subsection{Setting}

Consider a discrete-time labor market with a continuum of identical firms and identical, infinitely-lived workers. We denote the measure of firms by $N_{F}$ and we normalize the measure of workers to 1 . We allow for free entry of firms, so $N_{F}$ is endogenous. At each point in time, each worker is either employed at one of the firms or non-employed. The fractions of employed and non-employed workers at time $t$ are denoted by $e_{t}$ and $\bar{e}_{t}$ respectively, where $e_{t}+\bar{e}_{t}=1$. Likewise, each firm is either matched with a worker or unmatched, in which case it has a vacancy. The fraction of firms with vacancies is denoted by $v_{t}$. Employed workers stay in their job until their match with the firm gets destroyed by some exogenous shock. In each period this is the case for a fraction $\delta$ of the matches, after which the workers in question flow into non-employment and the jobs become vacant.

In our model, non-employed workers can decide whether they want to search for a job or not. This gives us a meaningful distinction between unemployment and non-participation. The non-participants are the non-employed workers who decide not to search because it is too costly, while the unemployed workers search at least once. We discuss this in more detail below. In each period a fraction $m_{W}$ of the non-employed workers flows to employment and a fraction $m_{F}$ of the vacancies gets filled. The fractions $m_{W}$ and $m_{F}$ are endogenous in our model and we will derive an expression for it in the next subsections. We make the usual assumption that the labor market is in steady state, meaning that the fraction of workers and firms in each state is constant over time, i.e. $e_{t}=e$ and $v_{t}=v \forall t$, where $e$ and $v$ are given by

$$
e=\frac{m_{W}}{m_{W}+\delta}
$$


and

$$
v=\frac{\delta}{m_{F}+\delta} .
$$

A worker who is employed in a specific period receives a wage $w$. The payoff of the firm for which she is working equals $y-k-w$, i.e. the difference between the value of produced output $y$, a capital cost $k$ and the wage paid to the worker. Non-participants have a payoff that is determined by two components: the value of their home production and the value of leisure, which together amount to a quantity denoted by $h$. An unemployed worker additionally receives unemployment benefits $b$. These values and the option value of search together determine the worker's reservation wage $w_{R}$. Firms with an unfilled vacancy do not produce, but still have to pay the capital cost. Their payoff therefore equals $-k$. All agents discount future payoffs at rate $\frac{1}{1+r}$.

We assume that a worker has to apply to jobs at the beginning of a period, but only learns whether she is accepted or not at the end of the period. Consequently, workers might want to send several applications simultaneously in order to reduce the risk of remaining unmatched. We allow workers to choose the number of applications $a$ that they want to send. Because of computational considerations, we impose a maximum $S$ on the number of jobs to which a worker can apply in a specific period. Since $S$ can be any finite number, this maximum is hardly restrictive. For each application the worker incurs a search cost $c>0$. This search cost differs amongst workers but is drawn from a common, non-degenerate distribution $F_{c}(c)$. One very useful simplification we make is that workers draw a new search cost parameter in each period. This captures the idea that the opportunity cost of job search is a random variable that is affected by things like having kids, health status, etc. If we, alternatively had assumed search cost to be worker specific, we would have to calculate search-cost-dependent reservation wages which would make the model a lot more complicated. Now we end up with a reservation wage which is the same for all workers. ${ }^{2}$ Since we only need the cross sectional search cost distribution we choose the simple option.

In models of consumer search, i.e. Burdett and Judd (1983) and Moraga-Gonzalez and Wildenbeest (2006), there usually is no rationing and each buyer is served. In a labor market model, the assumption of no rationing is unrealistic: firms typically hire only one or a subset of the applicants for a certain job. To allow for rationing we assume an urn-ball matching function, like in Albrecht, Tan, Gautier and Vroman (2004) and further assume that workers choose the firm that offers them the highest wage as in Gautier and Moraga-Gonzalez (2004). So, the matching process is as follows:

1. Workers draw a search cost $c$, decide to how many jobs they wish to apply and send that number of applications to random vacancies.

2. Each vacancy that receives at least one application, randomly selects a candidate and offers her a wage. Applications that are not selected are returned as rejections.

\footnotetext{
${ }^{2}$ Worker specific search cost could capture the idea that some workers are in a position to contact many employers because they have a good network or live in a location with many job opportunities while other workers have high search cost because they live in remote areas or they have very specific skills.
} 
3. Workers that receive one or more wage offers accept the highest one as long as it is higher than the reservation wage. Other wage offers are rejected.

The number of job applications and the posted wages are determined in a simultaneous-moves game. In the estimation procedure we will use a sample of the flow from non-employment to employment. This allows us to focus on the wage distribution for newly hired workers and to ignore the job-to-job transitions which are an additional reason for wage dispersion, see Burdett and Mortensen (1998). In this way we can isolate the search intensity contribution to wage dispersion and keep the model tractable. Finally, we focus on symmetric equilibria where identical firms have similar strategies. In the next subsections we discuss the workers' and firms' optimal strategies.

\subsection{The workers' problem}

The strategy of a worker with search cost $c$ consists of a reservation wage $w_{R}$ and a number of job applications $a(c)$ that she will send out to the firms. Since workers are ex ante identical, the reservation wage $w_{R}$ will be the same for all workers. However, workers learn their search cost $c$ before they start applying to the vacancies and may therefore differ in the number of jobs $a$ they apply for. We denote the fraction of non-employed workers sending $a$ applications by $p_{a}$. For some of these workers (fraction $p_{0}$ ) the search costs might be so high that it is not profitable for them to search even once in this period. They become non-participants. The other workers (fraction $1-p_{0}$ ) search at least once and are therefore considered to be unemployed. We denote the steady state fractions of unemployed and non-participating workers in the population by respectively $u$ and $n$ :

$$
n=p_{0}(1-e)
$$

and

$$
u=\left(1-p_{0}\right)(1-e)
$$

Since search is random, all firms are equally likely to receive applications. This implies that the expected number of applications per vacancy is equal to the total number of applications divided by the number of vacancies:

$$
\phi=\frac{(1-e) \sum_{a=1}^{S} a p_{a}}{v N_{F}}=\frac{\sum_{a=1}^{S} a p_{a}}{\left(1-p_{0}\right) \theta},
$$

where $v$ is the fraction of firms with vacancies and $\theta=\frac{v N_{F}}{u}$ denotes labor market tightness. Due to the infinite size of the labor market, the actual number of applications to a specific vacancy follows a Poisson distribution with mean $\phi$. This is not completely obvious because in a finite labor market more matches are realized for a given mean search intensity when the variance is zero. The key intuition why the number of applicants follows a Poisson in the limit and why all that matters is the average search intensity is that the probability that any two workers compete for the same job more than once is zero when workers apply to a finite number of jobs. Consequently, the event that application $i$ results in a job offer only depends on labor market tightness and the total number of applications, and is independent of the event that application $j$ 
results in a job offer. The number of competitors that a worker faces at a given firm also follows a Poisson distribution with mean $\phi$, again because there is an infinitum of workers. Assume that if two or more firms compete for the same worker, the worker picks the highest wage and the other firms have to open a new vacant position in the next period as in Albrecht et al. (2004). In case of $i$ other applicants, the probability that the individual in question will get the job equals $\frac{1}{i+1}$. Therefore, the probability $\psi$ that an application results in a job offer equals

$$
\psi=\sum_{i=0}^{\infty} \frac{1}{i+1} \frac{\exp (-\phi) \phi^{i}}{i !}=\frac{1}{\phi}(1-\exp (-\phi)) .
$$

Given the assumptions above, the number of wage offers that a worker receives follows a binomial distribution. ${ }^{3}$ More precisely, for a worker who sends $a$ applications the probability $\chi(j \mid a)$ to get $j$ job offers equals

$$
\chi(j \mid a)=\left\{\begin{array}{cl}
\left(\begin{array}{c}
a \\
j
\end{array}\right) \psi^{j}(1-\psi)^{a-j} & \text { if } j \in\{0,1, \ldots, a\} \\
0 & \text { otherwise }
\end{array}\right.
$$

We denote the fraction of non-employed workers that receive $j$ job offers by $q_{j}$. This fraction is equal to the product of $p_{a}$ (i.e. the fraction of non-employed workers sending $a$ applications) and the probability that these $a$ applications result in exactly $j$ job offers, summed over all possible $a$ :

$$
q_{j}=\sum_{a=j}^{S} \chi(j \mid a) p_{a}
$$

This notation allows us to give a simple expression for the matching probability $m_{W}$ that a non-employed worker flows into employment in the next period. It is equal to

$$
m_{W}=1-q_{0}=1-\sum_{a=0}^{S} p_{a}(1-\psi)^{a}
$$

In order to derive an expression for the reservation wage we specify two discrete time Bellman equations. The first one defines $V_{E}(w)$, i.e. the expected discounted lifetime income of a worker who is currently employed at a wage $w$ :

$$
V_{E}(w)=w+\frac{1}{1+r}\left((1-\delta) V_{E}(w)+\delta V_{N E}\right),
$$

where $V_{N E}$ denotes the value of being non-employed. Hence, the value of employment equals the sum of the wage $w$ and the discounted value of employment if the worker stays in the job (probability $1-\delta$ ) or the discounted value of non-employment if the match with the firm gets destroyed (probability $\delta$ ).

Non-employed workers face a trade-off: they must decide how many applications they want to send. Applying to many jobs is expensive but reduces the probability of remaining unmatched and results in a higher expected best offer. A non-employed worker with search cost $c$ chooses the number of applications $a$ in such a way that she maximizes her expected discounted lifetime payoff $V_{N E}^{c}$. This value is defined by

$$
V_{N E}^{c}=h+\max _{a}\left(\frac{1}{1+r}\left(\sum_{j=1}^{a} \chi(j \mid a) \int_{0}^{\infty} \max \left\{V_{N E}, V_{E}(w)\right\} d F_{w}^{j}(w)+\chi(0 \mid a)\left(I_{a>0} b+V_{N E}\right)\right)-a c\right)
$$

\footnotetext{
${ }^{3}$ See Albrecht, Gautier and Vroman (2006)
} 
Hence, the value of non-employment for a worker with search cost $c$ equals the sum of the home production $h$ and the expected discounted payoff of her optimal search strategy. If the worker sends $a$ applications, then she receives $j$ wage offers with probability $\chi(j \mid a)$. Each wage offer $w$ is a random draw from a wage offer distribution $F_{w}$ with corresponding density $f_{w} \cdot{ }^{4}$ In case the worker receives multiple job offers, she accepts the best one as long as that offer gives her a higher payoff than remaining non-employed. If the worker does not receive any offer, she gets unemployment benefits $b$ conditional on having sent at least one application (represented by the indicator function $I_{a>0}$ ) and she remains non-employed again in the next period. So, a necessary condition to receive UI benefits is to actively search for a job, as is the case in most OECD countries. The total cost of sending $a$ applications equals $a c$.

Ex ante, the non-employed workers do not know the value of the search cost that they will draw. Their expected value of non-employment is therefore equal to

$$
V_{N E}=\int_{0}^{\infty} V_{N E}^{c} d F_{c}(c)
$$

By evaluating equation (10) in $w_{R}$ and using the reservation wage property $V_{E}\left(w_{R}\right)=V_{N E}$, it follows that

$$
V_{N E}=\frac{1+r}{r} w_{R}
$$

Substituting this expression back in (10) and rewriting the result gives

$$
V_{E}(w)=\frac{1+r}{r+\delta}\left(w+\frac{\delta w_{R}}{r}\right)
$$

Next, we can use the equations (11) to (14) to obtain the worker's reservation wage.

$$
w_{R}=h+\int_{0}^{\infty} \max _{a}\left(\frac{1}{r+\delta} \sum_{j=1}^{a} \chi(j \mid a) \int_{w_{R}}^{\infty}\left(w-w_{R}\right) d F_{w}^{j}(w)+\chi(0 \mid a) I_{a>0} \frac{b}{1+r}-a c\right) d F_{c}(c) .
$$

which depends on the value of home production and the option value of search. One can easily show that this expression for the reservation wage satisfies Blackwell's (1965) sufficient conditions for a contraction mapping. Therefore, a unique value for the reservation wage $w_{R}$ exists.

In order to derive which fraction of the workers searches $0,1, \ldots, S$ times, we first determine the expected gain of searching one additional time. We denote this increment by $\Gamma_{a}$. From the expressions above it follows that $\Gamma_{a}$ is equal to

$$
\begin{aligned}
\Gamma_{1} & =\frac{1}{r+\delta} \zeta_{1}+(1-\psi) \frac{b}{1+r} \\
\Gamma_{a} & =\frac{1}{r+\delta}\left(\zeta_{a}-\zeta_{a-1}\right)-\psi(1-\psi)^{a-1} \frac{b}{1+r}, a=2, \ldots, S,
\end{aligned}
$$

where the first terms on the right-hand side reflect the expected wage increase of an additional application and the second parts reflects the change in the probability to receive UI benefits, $b$. When a worker starts searching once instead of being a non-participant, she becomes eligible to those benefits. When she considers

\footnotetext{
${ }^{4}$ We derive this wage offer distribution in the next subsection.
} 
searching $a$ rather than $(a-1)$ times, she realizes that she is less likely to continue to receive $b$, but more likely to find a well-paying job, giving an expected payoff that exceeds the reservation wage by

$$
\zeta_{a}=\sum_{j=1}^{a} \chi(j \mid a) \int_{w_{R}}^{\infty}\left(w-w_{R}\right) d F_{w}^{j}(w) .
$$

$\chi(j \mid a)$ is the probability to receive $j$ offers conditional on sending $a$ applications, given by (7). In that case she receives the expected maximum of $j$ draws from the wage offer distribution $F(w)$, but she has to give up the value of being non-employed, i.e. $w_{R}$. As long as $b$ is not too large and $\delta$ is not too close to $1, \Gamma_{a}$ is a decreasing function of $a$. This implies that workers continue searching as long as $\Gamma_{a}$ is larger than their search cost $c$. Hence, the fractions $p_{a}$ satisfy the following conditions:

$$
\begin{aligned}
& p_{0}=1-F_{c}\left(\Gamma_{1}\right) \\
& p_{a}=F_{c}\left(\Gamma_{a}\right)-F_{c}\left(\Gamma_{a+1}\right), a=1,2, \ldots, S-1 \\
& p_{S}=F_{c}\left(\Gamma_{S}\right)
\end{aligned}
$$

\subsection{The firms' problem}

In this section we derive the wage offer distribution for newly hired workers. A firm with a vacancy offers one of its applicants a wage $w$. In order to be attractive to both the firm and the applicant, this wage should be higher than the worker's reservation wage $w_{R}$, but lower than the value of the output that will be produced in case of a match, net of capital cost: $y-k$. Furthermore, the wage has to be higher than the legal minimum wage $w_{\min }$. Define $\underline{w}=\max \left\{w_{R}, w_{\min }\right\}$. The firm faces a trade-off within the interval $[\underline{w}, y-k]$ : posting a lower wage increases its payoff $y-k-w$ conditional on the worker accepting the offer, but it also increases the probability that the worker will reject the offer because of getting a better offer from an other firm.

Note that without a minimum wage, at least some workers must search more than once for a non-trivial equilibrium to exist, i.e. $p_{0}+p_{1}<1 .^{5}$ If this condition does not hold, there is no incentive for firms to post a wage higher than the reservation wage, as in Diamond (1971). However, given the strictly positive costs of search, this would imply that workers do not search in the first place and that the market would collapse. The introduction of a minimum wage leads to a different situation. If the minimum wage is sufficiently high, such that $\underline{w}=w_{\min }>w_{R}$, an equilibrium in which $p_{0}+p_{1}=1$ can exist. For this equilibrium to arise, some workers must have search costs that are low enough to let them search once but too high to let them search twice, while the remaining workers must have search costs that are very high. In that case the wage distribution is degenerate at $w_{\min }$.

Obviously, a degenerate wage distribution is not in line with what is typically observed in data, so we focus on the situation in which $p_{0}+p_{1}<1$ holds. ${ }^{6}$ For the same reasons as in Burdett and Judd (1983) and Burdett and Mortensen (1998) there exists no symmetric pure strategy equilibrium wage offer distribution for

\footnotetext{
${ }^{5}$ Throughout this paper we assume that at least some workers search, i.e. $p_{0}<1$. Otherwise, the market would not open.

${ }^{6} \mathrm{~A}$ second necessary condition for wage dispersion is that a strictly positive fraction of the workers receives exactly 1 job offer, i.e. $q_{1}>0$. Otherwise competition between the firms would push up the wages till $y-k$, again resulting in a degenerate wage distribution. It is straightforward to see that the condition $q_{1}>0$ is automatically satisfied by the structure of our model.
} 
firms under this condition. At any candidate pure-strategy-equilibrium wage there either exists a profitable $\varepsilon$ upward deviation or a downward deviation to $\underline{w}$. However, there exists a mixed strategy equilibrium in wage offers to newly hired workers. Let $F_{w}$ denote this equilibrium wage distribution. A firm that offers the lower bound of this distribution only attracts workers that do not compare wages. Firms that offer wages below $\underline{w}$ will never hire workers. Therefore, the lower bound of the wage distribution must be equal to $\underline{w}$. The expected payoff for a firm offering $\underline{w}$, referred to as $\pi(\underline{w})$, equals the product of $y-k-\underline{w}$ and the probability that the firm offers the job to a worker who does not get job offers from other firms:

$$
\pi(\underline{w})=(y-k-\underline{w}) \frac{1-e}{v N_{F}} q_{1} .
$$

In general, the expected payoff $\pi(w)$ to a firm offering a wage $w$ is equal to the product of $y-w$ and the probability that the firm selects an applicant for whom the $j-1$ other job offers all give a wage lower than $w$ :

$$
\pi(w)=(y-k-w) \frac{1-e}{v N_{F}} \sum_{j=1}^{S} j q_{j} F_{w}^{j-1}(w) .
$$

In equilibrium, each wage in the support of $F_{w}$ must give the same level of expected profits to a firm. Therefore, equating (19) and (20) gives an equal profit condition that implicitly defines the equilibrium wage distribution $F_{w}$ :

$$
\sum_{j=1}^{S} j q_{j} F_{w}^{j-1}(w)=q_{1} \frac{y-k-\underline{w}}{y-k-w} .
$$

Although we cannot obtain an explicit, closed-form expression for $F_{w}$, it will be useful for the estimation to derive such an expression for the inverse of $F_{w}$ by rewriting equation (21). We denote this inverse function by $w(z)$ and it is equal to

$$
w(z)=y-k-\frac{(y-k-\underline{w}) q_{1}}{\sum_{j=1}^{S} j q_{j} z^{j-1}} .
$$

Evaluating this expression in $z=1$ gives the upper bound $\bar{w}$ of the support of the wage distribution:

$$
\bar{w}=y-k-\frac{(y-k-\underline{w}) q_{1}}{\sum_{j=1}^{S} j q_{j}},
$$

which is clearly strictly smaller than $y$ as long as $q_{1}>0$. Hence, provided that at least some workers only get one job offer, firms never post wages up to the productivity level. After all, that would give the firm a payoff of zero with probability one, while posting a lower wage gives a strictly positive expected payoff, since some applicants do not compare wages.

An expression for the density function of posted wages $f_{w}$ can be derived by applying the implicit function theorem to equation (21). This yields

$$
f_{w}(w)=\frac{\sum_{j=1}^{S} j q_{j} F_{w}^{j-1}(w)}{(y-k-w) \sum_{j=2}^{S} j(j-1) q_{j} F_{w}^{j-2}(w)} .
$$

As noted above, the matching probability of a firm depends on its wage offer to the applicant. Given a wage offer $w$, it is equal to

$$
m_{F}(w)=\frac{1-e}{v N_{F}} \sum_{j=1}^{S} j q_{j} F_{w}^{j-1}(w)
$$


So, the probability to hire a worker at wage $w$ equals the probability of offering the job to a worker with $j-1$ other job offers that are all lower than $w$. An expression for the ex ante matching probability $m_{F}$, i.e. before drawing a wage from the wage offer distribution, can be derived by integrating equation (25) over the support of $F_{w}(w)$. This gives

$$
m_{F}=\frac{\left(1-q_{0}\right)(1-e)}{v N_{F}},
$$

where $1-q_{0}=m_{W}$ which is given by (9). So the matching rates are completely endogenous and impose more structure on the model than most other search models. Finally, we can derive the firm's value functions, which determine entry. A firm that is matched to a worker produces output $y$ and has to pay a capital cost $k$ and a wage $w$. In the next period, the firm is still operative with probability $1-\delta$ and it switches to a vacant position with probability $\delta$. Hence, the firm's value function $V_{F}(w)$ of being matched with a worker earning a wage $w$ is given by

$$
V_{F}(w)=y-w-k+\frac{1}{1+r}\left((1-\delta) V_{F}(w)+\delta V_{V}\right) .
$$

A firm that has a vacancy incurs the capital cost $k$, but does not produce. If the firm offers a wage $w$, it matches with probability $m_{F}(w)$, resulting in a value $V_{F}(w)$ in the next period. If the firm does not match (probability $1-m_{F}(w)$ ) it gets $V_{V}$ again. Hence, $V_{V}$ equals

$$
V_{V}=-k+\frac{1}{1+r}\left(\int_{\underline{w}}^{\bar{w}}\left(m_{F}(w) V_{F}(w)+\left(1-m_{F}(w)\right) V_{V}\right) d F_{w}(w)\right) .
$$

We assume free entry of vacancies: unmatched firms enter the market as long as the expected payoff is positive. Hence, in equilibrium $V_{V}=0$ must hold. Substituting this condition into equation (27) and solving for $V_{F}(w)$ gives

$$
V_{F}(w)=\frac{1+r}{r+\delta}(y-w-k) .
$$

Note that as a result of the equal profit condition we can write $m_{F}(w) V_{F}(w)$ as follows:

$$
\begin{aligned}
m_{F}(w) V_{F}(w) & =\frac{1+r}{r+\delta} \pi(w) \\
& =\frac{1+r}{r+\delta} \frac{1-e}{v N_{F}} q_{1}(y-k-\underline{w}) .
\end{aligned}
$$

Substituting (30) in (28) and using the free entry condition $V_{V}=0$ yields

$$
0=-k+\frac{1}{r+\delta} \frac{1-e}{v N_{F}} q_{1}(y-k-\underline{w})
$$

which implicitly determines the equilibrium number of firms present in the market.

\subsection{Efficiency}

An interesting policy question is whether the market is socially efficient given the existing heterogeneity and search cost distribution. The social optimum follows from maximizing a constraint social planner's problem. The planner can decide how many firms enter the market and how often a worker applies, but he cannot 
solve the coordination frictions. We let the planner maximize the steady state per-period output, net of capital cost. In each period a fraction $e$ of the workers is employed, producing $y$. The non-employed produce $h$ and incur the search cost $c$ for each application they send. Each of the $N_{F}$ firms present in the market has to pay the capital cost $k$. The planner is not concerned with redistributional issues. Therefore, the levels of the wages and the unemployment benefits are irrelevant.

Suppose that the planner lets $N_{F}$ firms enter the market and imposes $\left\{p_{0}, \ldots, p_{S}\right\}$ on the workers. If the planner wants a group of workers to search $S$ times, it is optimal to let this group consist of the individuals with the lowest search costs. Similarly, the workers that should not search at all are the ones with the highest search costs. Therefore, there is a one-to-one relationship between the set $\left\{p_{0}, \ldots, p_{S}\right\}$ and the function $a(c)$ which assigns the number of applications to an individual with search $\operatorname{cost} c$. The set $\left\{p_{0}, \ldots, p_{S}, N_{F}\right\}$ implies values for $\phi, \psi, m_{W}$ and $e$ analogous to the equations derived in section 2.2. Hence, total output $Y$ is given by

$$
Y\left(p_{0}, \ldots, p_{S}, N_{F}\right)=\frac{m_{w}}{\delta+m_{w}} y+\frac{\delta}{\delta+m_{w}} h-\frac{\delta}{\delta+m_{w}} \int_{0}^{\infty} a(c) c d F_{c}(c)-N_{F} k .
$$

The social planner chooses the values $\left\{p_{0}^{*}, \ldots, p_{S}^{*}, N_{F}^{*}\right\}$ that maximize this expression. Hence, he solves

$$
Y^{*}=\max _{p_{0}, \ldots, p_{S}, N_{F}} Y\left(p_{0}, \ldots, p_{S}, N_{F}\right)
$$

subject to the conditions $\sum_{a=0}^{S} p_{a}=1, p_{a} \in[0,1] \forall a$, and $N_{F} \geq 0$. Since our estimation method provides us with estimates of $y, h$, and $F_{c}(c)$, we can numerically solve this maximization problem and confront the market's with the planner's outcome. We do this in section 5.3.

\section{Maximum likelihood estimation}

Estimation of the model requires two kinds of data. First of all, we need cross-sectional wage data for newly hired workers who enter from unemployment. Our source for this sort of information is the Dutch AVO data set, which contains information on the Dutch Labor market. We will discuss this data set in more detail in section 4. Secondly, some aggregate statistics on the labor market are needed. For example, we demand information on the number of vacancies $v N_{F}$ in the market and on the fractions of employed $(e)$, unemployed $(u)$ and non-participating $(n=1-e-u)$ individuals. Accurate data to estimate these variables are in general readily available. They are provided by most statistical agencies and they are usually not only available for the labor market as a whole, but also for submarkets. Furthermore, calculating the household production requires information on the level of the unemployment benefits. Without loss of generality, the unemployment benefits $b$ can be defined as the product of a replacement rate $\rho$ and the average wage. Typically, an estimate for $\rho$ can easily be obtained from macro-data.

Two other parameters have to be fixed exogenously: the maximum number of applications per period $S$ and the discount factor $\frac{1}{1+r}$. One can easily test whether the estimation results are sensitive to the values chosen for these parameters, but in general this does not seem to be the case. Increasing $S$ from for example 30 to 40 does not change the results since there is only a small difference in expected payoff between searching 
30 or 40 times. Furthermore, it is important to realize that choosing a different value for the interest rate only affects the scale of the search cost distribution $F_{c}(c)$. It does not change the estimates that we get for the search fractions $p_{a}$, the job offer probability $\psi$, the job offer fractions $q_{j}$, or the productivity $y$. Likewise, a different value for the replacement rate $\rho$ only changes the decomposition of the reservation wage into $b$ and $h$.

These parameters, the data, the structure of the model and the steady state assumption provide us with all the information that we need to estimate the search cost distribution. We now give a short outline of the estimation algorithm. The first step is to calculate $p_{0}$. From equation (3), it follows that it equals the ratio of the fraction of non-participants in the population and the fraction of non-employed:

$$
p_{0}=\frac{n}{1-e} .
$$

We estimate the other fractions $p_{a}$ by maximizing the likelihood of the observed wages. Note that a distribution for $p_{a}$, together with $v, u$ and the urn-ball type of matching function that follows from (5) and (6), implies a job offer probability $\psi$. This job offer probability is the key parameter in the mapping from the number of applications $p_{a}$ to the number of job offers $q_{j}$. Given estimates for the productivity $y$, the capital cost $k$, and the lower bound $\underline{w}$ of the support of the wage offer distribution $F_{w}(w)$, we can calculate the upper bound $\bar{w}$ of the support by using equation (23). Then, we can solve equation (21) to get the full wage offer distribution and calculate the associated density from (24).

Note that, as in many models with on-the-job search, cross-sectional wages are not representative for the wages that are offered by the firms, but only for the wages that are accepted by the workers. High wage offers are more likely to be accepted than low wage offers, so the distributions of the offered wages and the accepted wages differ from each other. We denote the distribution of the accepted wages by the unemployed workers by $G_{w}$. Conditional on receiving at least one job offer, a worker will only accept a wage that is lower than some value $w$ if all the $j$ offers that she receives after sending $a$ applications are lower than $w$. This means that $G_{w}(w)$ can be derived from $F_{w}(w)$ as follows:

$$
G_{w}(w)=\frac{\sum_{j=1}^{S} q_{j} F_{w}^{j}(w)}{1-q_{0}} .
$$

It is straightforward to show that $G_{w}(w)$ first-order stochastically dominates $F_{w}(w)$. Taking the first derivative of this expression with respect to $w$ gives $g_{w}(w)$, the density of the accepted wages:

$$
g_{w}(w)=\frac{\sum_{j=1}^{S} j q_{j} F_{w}^{j-1}(w) f_{w}(w)}{1-q_{0}} .
$$

The density $g_{w}(w)$ has a very flexible form: it can be strictly upward sloping, but also U-shaped or bellshaped. This is demonstrated in figure 1 , which displays the wage density for four different sets $\left\{p_{0}, p_{1}, \ldots, p_{S}\right\}$ while keeping the other parameters fixed to some arbitrarily chosen values $(\underline{w}=0, y-k=20, \theta=1)$. If many workers search very little, then a specific firm with an applicant does not face much competition from other firms. As a result, a large part of the probability mass is at low wages. Conversely, if enough 
workers send many applications, then firms have an incentive to post relatively high wages as well. Hence, by choosing the right values $\left\{p_{0}, p_{1}, \ldots, p_{S}\right\}$ we can fit a wide range of possible shapes of the wage distribution. This flexibility is an important advantage compared to existing search models with identical workers and jobs, like for example Burdett-Mortensen (1998). These models exclusively imply strictly increasing wage densities, while existing wage distributions are typically hump-shaped.

Note that the productivity and the capital cost only enter the expression for $g_{w}(w)$ as the difference $y-k$. Hence, the maximum likelihood procedure will only provide us with an estimate for the net productivity $\hat{y}=y-k$. Ex post however, we can retrieve the value for $k$ by rewriting equation (31):

$$
k=\frac{1}{r+\delta} \frac{1-e}{v N_{F}} q_{1}(\widehat{y}-\underline{w}) .
$$

Subsequently, the productivity $y$ simply equals the sum of $\widehat{y}$ and $k$.

Kiefer and Neumann (1993) suggest to use the lowest wage and the highest wage in the sample to estimate the bounds of the wage offer distribution. ${ }^{7}$ Although this approach gives superconsistent estimates, we do not follow this suggestion, since these order statistics are quite sensitive to outliers. Instead, we estimate the productivity $\hat{y}$ and the lower bound $\underline{w}$ as parameters in our maximum likelihood problem. Together they imply a value for the upper bound $\bar{w}$ as was shown in equation (23). We allow for measurement error to explain observations outside the bounds of the support. To be precise, we assume that the observed wage $\tilde{w}$ depends on the true wage $w$ and a random error term $\varepsilon$ in the following way

$$
\tilde{w}=w \varepsilon
$$

where $\varepsilon$ has a $\log$-normal distribution with parameters $\mu=0$ and $\sigma=\operatorname{var}(\log (\varepsilon))$. We will estimate the value of $\sigma$, which provides a natural test on the fit of the model. If we find a very large value for $\sigma$, then a large part of the variation in the data cannot be explained by the model, implying that the model performs relatively poor and measurement error is basically a free parameter. If we however find a small value of the standard deviation, this can be seen as supporting evidence for the model. The density of the observed wages can now be obtained by integrating over all possible values of the error term. If a wage $\tilde{w}$ is observed, the error term must have been in the interval $[\widetilde{w} / \bar{w} ; \widetilde{w} / \underline{w}]$ Hence, $g_{\widetilde{w}}(\widetilde{w})$ is equal to

$$
g_{\widetilde{w}}(\widetilde{w})=\int_{\widetilde{w} / \bar{w}}^{\widetilde{w} / \underline{w}} g_{w}(\widetilde{w} / \varepsilon) \frac{1}{\varepsilon} \eta(\varepsilon) d \varepsilon,
$$

where $\eta(\varepsilon)$ denotes the log-normal density and $g_{w}$ is given by (36) which basically captures the entire structure of the model. The integral in this equation must be calculated numerically, since it depends on $F_{w}(w)$, for which no explicit expression exists.

Assuming independence of the $N$ observations, the likelihood of the sample is now equal to the product of $g_{\widetilde{w}}\left(\widetilde{w}_{i}\right)$ for each individual $i$. So, the maximum likelihood problem is given by

$$
\max _{p_{1}, \ldots, p_{S}, \sigma, \underline{w}, y} \frac{1}{N} \sum_{i=1}^{N} \log g_{\widetilde{w}}\left(\widetilde{w}_{i}\right),
$$

\footnotetext{
${ }^{7}$ See also Donald and Paarsch (1993) for a discussion of the use of order statistics to estimate the bounds of distributions.
} 
subject to the conditions $\sum_{a=0}^{S} p_{a}=1, p_{a} \in[0,1] \forall a$ and $w_{\min } \leq \underline{w} \leq y$. As is common in these kind of models, the reservation wage is only identified if it exceeds the minimum wage. In that case $w_{R}=\underline{w}$. Otherwise, we can only derive some bounds on $w_{R}$. The upper bound in that situation is given by $\underline{w}$, while the lower bound is defined by equation (15) and the restriction $h=0$. This is not a major problem for the empirical analysis in section 4 and 5 . We will use the point estimate if possible and the bounds otherwise.

From the maximum likelihood estimates we can derive the search cost distribution by using equation (18). This requires the calculation of the marginal gains of search $\Gamma_{a}$ as given in equation (16). Note that this variable depends on the integral $\int_{w_{R}}^{\infty} w d F_{w}(w)^{j}$. To simplify the calculation of this integral, we apply a change of variables. This results in

$$
\int_{w_{R}}^{\infty} w d F_{w}^{j}(w)=\int_{\underline{w}}^{\bar{w}} w d F_{w}^{j}(w)=\int_{0}^{1} j w(z) z^{j-1} d z,
$$

where $w(z)$ represents the inverse of the wage distribution given in (22). Substituting this in equation (17) gives

$$
\zeta_{a}=\sum_{j=1}^{a} \chi(j \mid a) \int_{0}^{1} j\left(\widehat{y}-w_{R}-\frac{(\widehat{y}-\underline{w}) q_{1}}{\sum_{j=1}^{S} j q_{j} z^{j-1}}\right) z^{j-1} d z
$$

The marginal gains of an additional application can then be calculated from (16) where the equilibrium value for the separation rate $\delta$ follows from the steady state condition given in equation (1):

$$
\delta=\frac{\left(1-q_{0}\right)(1-e)}{e} .
$$

We can use $\Gamma_{a}$ as cut-off points of the search cost distribution $F_{c}(c)$. Figure 2 gives an example of how we can estimate the search cost distribution from the observed wage distribution. First, the expected maximum wage offer of applying to $a$ jobs, $\zeta_{a}$, corresponds to a point on $G_{w}(w)$ (panel 1). The shape of $G_{w}(w)$ determines the marginal benefits of search, $\Gamma_{a}$. For example, in a close to competitive economy where workers are the scarce factor, all applications result in an offer, wages are close to net productivity and $\Gamma_{1}$ will be very large, while the values for $\Gamma_{a>1}$ would be close to zero. In figure 2 , the marginal benefits of applying to more than 1 job are positive but decreasing. A worker realizes that his finite number of applications does not affect the wage distribution and takes $\Gamma_{1}, \ldots \Gamma_{S}$ as given. He compares these marginal gains to the marginal cost of an additional application, i.e. his search cost $c$, to determine his optimal search intensity (panel 2). For example, if his search cost equals $c_{\text {low }}$ in the second panel, then he should apply four times. On the other hand, if his search cost is $c_{h i g h}$, it would be optimal not to search since the marginal gain of the first application is already smaller than the marginal cost.

An econometrician argues in exactly the opposite way. When he observes (or estimates) that a fraction $p_{0}$ of the workers does not search at all, he concludes that the search cost $c$ of each of these individuals must have exceeded $\Gamma_{1}$. This provides him with one point of the search cost distribution $F_{c}(c)$, i.e. $p_{0}=1-F_{c}\left(\Gamma_{1}\right)$ (panel 3). Similarly, $F_{c}\left(\Gamma_{4}\right)-F_{c}\left(\Gamma_{5}\right)$ gives the fraction of workers with search costs that are such that if they search 4 times or less, the marginal benefits exceed the marginal cost but if they search 5 times, the marginal cost of search exceeds the marginal benefits. So, this determines the fraction of workers that searches 4 times, 
$p_{4}$. In the estimation procedure, we start with the wage distribution which gives information on the fraction of workers who received $j$ offers, $q_{j}$. The structure of the model relates $\left\{q_{0}, \ldots, q_{S}\right\}$ to $\left\{p_{0}, \ldots, p_{S}\right\}$ and implies values for the marginal benefits of searching $a$ times. Together, this determines $S$ points on the search cost distribution. Hence, if for example the difference between $\Gamma_{1}$ and $\Gamma_{2}$ is large but $p_{1}$ is nevertheless small, it suggests that $F_{c}(c)$ is flat in that region.

In section 5.3, where we solve the social planner's problem, we need the full distribution $F_{c}(c)$. An approximation of this distribution can be obtained by interpolating the $S$ cut-off points. In this paper, we use linear interpolation. Note that we also have to extrapolate the distribution, because we do not know the distribution of the search costs among the non-participants. We only know that for each one of them the search cost $c$ is larger than $\Gamma_{1}$, since otherwise they would have searched at least once. However, for the social planner it makes a difference whether the search cost of a specific non-participant is only slightly higher than $\Gamma_{1}$ or much higher. Therefore, we consider three different cases: (i) all non-participants have a search cost that is equal to $\Gamma_{1}$, (ii) all non-participants have a search cost that is infinitely large, and (iii) the search cost distribution keeps increasing linearly for $c>\Gamma_{1}$, with the same slope as just before $\Gamma_{1}$, until it reaches 1 . In this case $F_{c}(c)$ is given by

$$
F_{c}(c)=\left\{\begin{array}{ll}
1-p_{0}+\frac{p_{1}}{\Gamma_{1}-\Gamma_{2}}\left(c-\Gamma_{1}\right) & \forall c \in\left[\Gamma_{1}, \Gamma_{0}\right) \\
1 & \forall c \geq \Gamma_{0}
\end{array}, \text { where } \Gamma_{0}=\Gamma_{1}+\frac{p_{0}}{p_{1}}\left(\Gamma_{1}-\Gamma_{2}\right) .\right.
$$

The first and the second case respectively provide an upper bound and a lower bound on the planner's outcome. For this reason, we refer to them as the maximum case and the minimum case. The third case (linear case) on the other hand can be seen as the best possible estimate. The three different cases are displayed in the third panel of figure 2 .

For solving the social planner's problem, values for the unemployment benefits $b$ and the household production $h$ are required. The value for $b$ can be calculated from the replacement rate $\rho$ and the average wage. To be precise, $b$ equals

$$
\begin{aligned}
b & =\rho \int_{\underline{w}}^{\bar{w}} w d G_{w}(w) \\
& =\rho\left(w_{R}+\frac{1}{1-q_{0}} \sum_{j=1}^{S} q_{j} \int_{\underline{w}}^{\bar{w}}\left(w-w_{R}\right) d F_{w}^{j}(w)\right) \\
& =\rho\left(w_{R}+\frac{1}{1-q_{0}} \sum_{a=1}^{S} p_{a} \zeta_{a}\right) .
\end{aligned}
$$

This result can be used to derive an estimate for $h$, the combined value of leisure and household production, from equation (15). The value of $h$ basically follows from the difference between the reservation wage and the cost of search. Using the same simplifications as above, we can rewrite this expression as

$$
h=w_{R}-\int_{0}^{\infty} \max _{a}\left(\frac{1}{r+\delta} \zeta_{a}+\chi(0 \mid a) I_{a>0} \frac{b}{1+r}-a c\right) d F_{c}(c)
$$

We can split the support of $F_{c}(c)$ into the intervals $\left[\Gamma_{S+1}, \Gamma_{S}\right),\left[\Gamma_{S}, \Gamma_{S-1}\right), \ldots,\left[\Gamma_{2}, \Gamma_{1}\right),\left[\Gamma_{1}, \Gamma_{0}\right]$, where $\Gamma_{S+1}$ and $\Gamma_{0}$ respectively denote the lower bound and the upper bound of the support of $F_{c}(c)$ (see panel 3 of 
figure 2). Due to the linear interpolation, $f(c)$ is constant on each of these intervals. Let $f_{a}$ denote the value of $f(c)$ on the interval $\left[\Gamma_{a+1}, \Gamma_{a}\right)$. Then the following expression holds:

$$
f_{a}=\frac{F\left(\Gamma_{a}\right)-F\left(\Gamma_{a+1}\right)}{\Gamma_{a}-\Gamma_{a+1}}=\frac{p_{a}}{\Gamma_{a}-\Gamma_{a+1}} .
$$

Substituting this in (46), we can write

$$
\begin{aligned}
h & =w_{R}-\sum_{a=1}^{S}\left(\int_{\Gamma_{a+1}}^{\Gamma_{a}} \frac{1}{r+\delta} \zeta_{a} f_{a} d c+\int_{\Gamma_{a+1}}^{\Gamma_{a}} \chi(0 \mid a) I_{a>0} \frac{b}{1+r} f_{a} d c-\int_{\Gamma_{a+1}}^{\Gamma_{a}} a c f_{a} d c\right) \\
& =w_{R}-\sum_{a=1}^{S} p_{a}\left(\frac{1}{r+\delta} \zeta_{a}+\chi(0 \mid a) I_{a>0} \frac{b}{1+r}-\frac{1}{2} a\left(\Gamma_{a}+\Gamma_{a+1}\right)\right) \\
& =w_{R}-\frac{1}{r+\delta} \sum_{a=1}^{S} p_{a}\left(\zeta_{a}-\frac{1}{2} a\left(\zeta_{a+1}-\zeta_{a-1}\right)\right)-\frac{b}{1+r}\left(q_{0}-p_{0}\right),
\end{aligned}
$$

where we define $\zeta_{S+1}=\zeta_{S}$ to simplify notation. This relates $h$ to variables that we can estimate or directly observe.

\section{Data and empirical issues}

\subsection{Parameters}

We apply the model developed in the previous sections to the Dutch labor market. In the next subsection we describe the wage data that we use for this. First, we explain how we obtain estimates for the exogenous parameters. We start by setting the maximum number of applications $S$ equal to 30 . As mentioned in the previous section, the estimation results are not sensitive to this specific value. Choosing a higher number increases the number of parameters that has to be estimated without gaining much in terms of fit.

We use data from Statistics Netherlands to get a value for the replacement rate $\rho$. This data shows that the Dutch government spent 4075.5 million euros on unemployment benefits in 2005. The stock of unemployed contained on average 305140 individuals in that year. Hence, 13350 euros were paid per individual. Since the average income amounted to 33000 euros, we set the average replacement rate $\rho$ equal to 0.40 . This is exactly the same value that Hornstein, Krusell and Violante (2006) use. In order to determine a reasonable value for the interest rate $r$, we first have to decide on the length of a period in our model. Since the length of a period does not play a role in our estimation procedure, we cannot estimate it. Therefore, we rely on Van Ours and Ridder (1993), who study vacancy durations and who give evidence that workers indeed search non-sequentially. They find that the period it takes between posting and filling a vacancy conditional on having candidates is about four months. Given an annual interest rate of $5 \%$, this implies that $r=0.0164$. It is worth stressing that our estimates for the search fractions $p_{a}$, the job offer probability $\psi$, the job offer fractions $q_{j}$, or the productivity $y$ do not depend on this length. It only affects the interest rate, which in turn only rescales the search cost distribution.

Values for the labor market statistics $e, u$, and $n$ are also obtained from Statistics Netherlands. This data is available for each combination of calendar year, gender, education, and age cohort. We use that 
information to calculate the value for our sample, taking into account the composition of the sample. The number of vacancies $v N_{F}$ is calculated indirectly: it equals the product of the average labor market tightness $\theta$ (0.70 in our sample) and the unemployment rate $u$. In section 4.4 we present the values for these parameters in more detail.

\subsection{AVO data set}

The source for the wage data that we use in the empirical application is the AVO data set ${ }^{8}$ of the Dutch Labor Inspectorate, which is part of the Ministry of Social Affairs and Employment. The data are collected annually from the administrative wage records of a sample of firms. The sample period spans from 1992 to 2002. The sampling procedure consists of two stages. In October of each year, first a stratified sample of firms in the private sector is drawn from the Ministry's firm register. The strata are based on industrial sector and firm size (measured by the number of employees). In the second stage, workers are sampled from the administrative records of the firms. Information is collected at two points in time: one year before the sampling date and the sampling date itself. The number of workers sampled depends on the firm size, the number of workers who are newly hired, who stayed in their job or who quited the firm, and the number of workers covered by collective labor agreements. The data set contains sampling weights for both the firm strata and the employees. For the firm the weight is equal to the inverse of the probability that the firm is sampled, while for the workers it corresponds to the inverse of the probability that the worker was selected from all employees at the firm. Multiplying these values gives the weight that can be used to calculate sample statistics for the workers.

A consequence of the sampling design is that we do not observe flows that occur between the two sampling dates. Our assumption that the length of one period in the model equals four months implies that we only observe the time points $t=0,3,6 \ldots$ in the AVO data set. Workers may have experienced other employment and unemployment spells between these moments of observation. Note that this is not a major problem for our analysis. The only assumption we must make is that the exact moment at which a newly hired worker entered his job does not affect his wage at the sampling date. This assumption seems very reasonable, given the fact that workers in general get salary increases only once a year.

A big advantage of this administrative data set compared to survey data is its precision. Missing values are rare and some variables are observed in great detail. ${ }^{9}$ For example, the data set distinguishes seven different wage components, which together add up to the total compensation for the worker. These components include, besides the basic wage, also personal bonuses, commuting allowances and the monetary value of wage in kind. In our study, we do not need the exact division of the wage, but the fact that all these components are reported allows us to really determine the total payoff of each worker.

Besides the wage information the data set also contains background characteristics of both workers and jobs. For example, we know the gender of the individual and her age and educational level. For the

\footnotetext{
${ }^{8} \mathrm{AVO}$ is the Dutch acronym for Terms of Employment Study.

${ }^{9}$ Nevertheless, some measurement error seems present in the data. We discuss this topic in more detail in subsection 4.4 .
} 
educational level of a worker, the survey reports the highest diploma obtained. We transform this into years of completed education using the design of the Dutch schooling system. With respect to the nature of the jobs, information is available on sector of industry, firm size and type of occupation. The sector of industry is coded according to the Dutch National Industrial Activity Classification (SBI'93) of Statistics Netherlands which is roughly similar to the SIC classification. We follow the rough division, which contains the following eleven sectors: agriculture, industry, education, construction, trade and reparation, hotel and catering, transport and communication, financial services, other services, health care, and culture and recreation. The firm size is measured by the number of employees of the firm at the sampling moment and the variable provided information on the nature of the occupation distinguishes between seven types of jobs: simple technical activities, administrative jobs, work in automation, commercial jobs, service providing jobs, creative jobs and management jobs.

Furthermore, we observe what type of contract a worker has. Most workers are covered by a collective employment agreement (CAO), which is bargained over at the sectoral level, or by some leading firms within the sector. The Minister of Social Affairs and Employment can declare this agreement legally binding for all other firms in the same sector, implying that these firms must offer the same terms of employment to its employees. This is labelled AVV. Some large companies have their own collective employment agreement. Finally, there are also workers who have a bilateral bargained wage contract. These workers are typically employed at higher positions in the firm. It is important to note that the existence of collective labor agreements does not rule out wage dispersion. A typical collective labor agreement provides many different salary scales and to a large extent firms can determine themselves according to which salary scale they will pay the newly hired worker. Furthermore, firms can also use bonuses and allowances to pay a worker a salary that exceeds the $\mathrm{CAO}$ wages.

A last important variable measures the job level on a eight-point scale. The lowest value (1) corresponds to jobs that consist of "very simple, continuously repeating activities, for which no education and only a little experience is required and which are performed under direct supervision". At the other end of the spectrum, a job is classified in the highest job level (8) when it implies "managing large companies or comparable departments or organizations " (Venema et al., 2002). The number of observations in job level 7 and 8 is relatively small. Therefore, we combine these workers with the ones in job level 6 .

For our analysis, we select the workers who flow from unemployment to employment. As argued before, we can isolate the contribution of search frictions to wage dispersion in this way. We further restrict the sample by focussing on workers with an almost full-time job. More precisely, we select all workers who work for at least 32 hours per week, which corresponds to $80 \%$ of a typical working week of 40 hours. The rationale for this selection is that the behavior of part-time workers might differ substantially from the behavior that we try to describe in our model. Moreover, the labor markets for part-time and full-time jobs are almost completely separated in the Netherlands, implying that these two groups of workers hardly compete with each other for a job. We also exclude individuals below 23 years of age and above 65 years. Individuals 
above 65 face mandatory retirement and a lower minimum wage applies to workers below 23 years of age. Hence, both groups cannot be considered to be identical to the rest of the workers.

Because of missing variables, we cannot use the samples of 1992 to 1995 and 1999. Hence, we use data from six waves (1996 to 1998 and 2000 to 2002). We correct the wage data for inflation by using a wage index and calculate the hourly wage for each worker by dividing her monthly wage by the number of hours worked. In section 4.4 we give some descriptive statistics of the sample, but first we describe in the next subsection how we partition the labor market into five segments.

\subsection{Segments}

In the theoretical model we made two important assumptions about the labor market. First, we assume that, apart from measurement error, differences in search cost are the only source of wage dispersion amongst individuals. Secondly, we consider a closed labor market, which means that no new workers or firms can enter and that the matching probability only depends on the strategy of the agents that are present in the market. In reality, workers obviously earn different wages for many reasons. Therefore, we first create approximately homogeneous segments correcting for observed heterogeneity and we assume that our model holds in each of those segments. The more segments one creates, the more homogeneous they will be; however, at the same time, the stronger the assumption is that we do not allow the best worker in segment $i$ to compete with the worst worker in segment $i+1$. As a compromise, we construct five segments. We assume that these segments constitute separate labor markets within the economy and that each worker and each firm is active in exactly one of the five submarkets. Further, we assume that within a segment all workers and all firms are homogeneous.

In order to create the segments, we construct a worker skill index $L_{s}$ and a job-complexity index $L_{c}$, as in Gautier and Teulings (2006). We create the skill index for the workers by regressing the logarithm of an individual's wage $w_{i}$, denoted by $\omega_{i}$, on all her observable characteristics: her years of education, her years of working experience ${ }^{10}$ (also squared and cubed), interaction terms between education and experience, and year dummies. Hence, we assume the linear relationship

$$
\omega=X_{s} \beta_{s}+\varepsilon_{s}
$$

where $\beta_{s}$ is a vector of coefficients and $\varepsilon_{s}$ is an error term. The matrix $X_{s}$ contains the explanatory variables. Next, we define the skill $L_{s}$ of an individual as the predicted value following from this regression:

$$
L_{s}=X_{s} \hat{\beta}_{s}
$$

where $\hat{\beta}_{s}=\left(X_{s}^{\prime} X_{s}\right)^{-1} X_{s}^{\prime} \omega$. Likewise, we construct a complexity measure for the jobs. We regress the logarithm of the wage paid by firm for this job on several job and firm characteristics:

$$
\omega=X_{c} \beta_{c}+\varepsilon_{c}
$$

\footnotetext{
${ }^{10} \mathrm{As} \mathrm{common}$ in literature, we define work experience as a function of age and the years of schooling. To be precise, we assume the following relation: experience $=($ age - years of education -6$) / 50$, where rescaling is applied for reasons of computational convenience.
} 
where $X_{c}$ includes a constant, dummy variables for the sector, the type of contract for this job, the job level, occupation, and year dummies. ${ }^{11}$ The complexity $L_{c}$ of the job is again defined as the predicted value of the regression:

$$
\begin{aligned}
L_{c} & =X_{c} \hat{\beta}_{c} \\
& =X_{c}\left(X_{c}^{\prime} X_{c}\right)^{-1} X_{c}^{\prime} \omega .
\end{aligned}
$$

The estimation results of these regressions are displayed in table 1 and 2 . The fit is good and most coefficients are in line with what is usually found in Mincerian type wage regressions. For example, an extra year of education increases $\log$ (wage) by 0.075 for school-leavers, but this effect is smaller for more experienced workers. In the job complexity regression, $\log$ (wage) is increasing in the job level. The correlation between the skill level and the complexity level is 0.58 . Hence, there is positive assortative matching in the labor market: better skilled workers have more complex jobs. We create the segments accordingly. A straightforward way of achieving this, is by defining:

$$
\Upsilon\left(L_{s}, L_{c}\right)=e^{L_{s} L_{c}}
$$

Next, we define the five segments as the quantiles of $\Upsilon\left(L_{s}, L_{c}\right) \cdot{ }^{12}$

If we repeat the skill and the complexity regression on each of the segments separately, we observe indeed that the segments are much more homogeneous than the labor market as a whole. For example, performing the skill regression on the first segment gives an $R^{2}$ of only 0.048 while for the whole sample it is 0.358 . This means that only a negligible fraction of the wage dispersion in this segment can be attributed to differences human capital factors like education and experience. The complexity regression can explain a slightly larger part of the wage variation $\left(R^{2}=0.188\right)$, but again considerably less than in the entire labor market. There $R^{2}$ equalled 0.475 . We interpret this as evidence that differences in search cost are the driving force behind wage dispersion in this segment. The same conclusion holds for the other segments. The only segment that calls for some circumspection in the interpretation of the results is the fifth. There the $R^{2}$ values of the skill and the complexity regression are 0.222 and 0.256 respectively, implying that a relatively large part of the heterogeneity is not filtered out.

\subsection{Descriptive statistics}

In this subsection we present the labor market statistics that we use in the estimation of the model as well as some descriptive statistics of the AVO data set. A first issue is that we discard some observations in order to prevent that our estimate of $\sigma$ is determined by outliers. Inspection of the data shows that in each segment some individuals are earning either very low or very high wages compared to other workers. It seems likely

\footnotetext{
${ }^{11}$ Although we also observe the size of the firm, we do not include this variable in the job complexity regression to avoid endogeneity problems.

${ }^{12}$ We have experimented with other definitions of the segments as well. This did not change any of the main conclusions. The advantage of this one above defining $\Upsilon$ as $E[w \mid s, c]$ is that our measure is more conservative in the sense that less wage variation within segments can be explained by observable characteristics.
} 
that the workers earning these wages are not representative for the rest of the segment. They probably earn these very high or low wages for other reasons than sending few or many applications. They might possess very specific skills or we might just have misclassified them and put them in the wrong segment. Therefore, we calculate the 10th percentile $w_{0.1}$, the median $w_{0.5}$ and the 90 th percentile $w_{0.9}$ of the wage distribution in each segment and we delete observations that are smaller than $w_{0.5}-\frac{3}{2}\left(w_{0.5}-w_{0.1}\right)$ or larger than $w_{0.5}+\frac{3}{2}\left(w_{0.9}-w_{0.5}\right)$. In case of a normal distribution, this procedure would lead to deleting $2,7 \%$ of the observations at both the top and the bottom of the distribution. Instead, the wage distributions are skewed to the right, resulting in removal of slightly more observations in the right tail (on average 3.8\%) than in the left tail (1.4\%).

After discarding the outliers we still observe that a small but strictly positive fraction (between $0.7 \%$ and $1.9 \%$ ) of the workers in the lowest three segments earns a wage that is lower than the legal minimum wage, which equals 7.51 euros per hour. Given the strict enforcement of labor laws in the Netherlands, it seems highly unlikely that these workers actually earn such a low wage. Therefore, we interpret this phenomenon as evidence of reporting mistakes in either the monthly wage or in the number of worked hours. Our model can easily deal with this, since we explicitly allow for measurement error in the data.

The values of the labor market statistics are displayed in table 3 . As the table shows, the labor market conditions are clearly increasing in the segment number. Compared to workers in a low segment, workers in a high segment are (i) more likely to be employed and (ii) more likely to search for a job when non-employed. The table also presents the number of vacancies and some characteristics of the wage distribution for each of the segments. As one would expect, the average wage is strictly increasing in the segment number. In the next subsection we will explore how these stylized facts affect the search strategy of the various types of workers and we will estimate their search cost distributions.

Table 4 presents some descriptive statistics of the AVO data set. It lists the mean and the standard deviation for several worker and job characteristics. A first observation is that workers in higher segments are better educated. Workers in segment 5 have on average completed almost seven years of education more than the workers in segment 1 . This difference corresponds to more than $80 \%$ and is strongly significant. Higher segments contain more men, but there are no large differences in the average age. Not surprisingly, workers in the higher segments are working more often in the service sector and less often in trade or industry.

The type of contract and the firm size seem relatively comparable across the segments. Most workers are covered by an industry wide collective employment agreement and the median firm size is between 50 and 99 for segment 1 to 4 and between 100 and 199 for segment 5. A strong positive correlation (0.79) exists between the segment number and the variable job level. This is not surprising, given that this variable aims to measure job complexity, which is one of the two components that we used to create the segments. Note that in segments 1 to 4 the fraction of workers with job level higher than 4 is virtually zero. In the highest segment however, it equals $58 \%$. This observation is reinforced by the fact that almost all managers are classified in segment 5 . 


\section{Results}

\subsection{Market equilibrium}

We estimate the model for each for the five segments separately. The estimation results are shown in table 5. To ease the reading, the fractions $p_{a}$ and $q_{j}$ that appear in the table are conditional on searching at least once. A first interesting observation with respect to the search intensity probabilities is that on the one hand the first and the second segment give similar results and on the other hand segment 3, 4, and 5 are much alike. In the first two segments, the majority of the searchers sends out one job application per period. The remaining workers search almost always twice. In the three highest segments, this pattern is reversed. Most individuals searching for a job send out two applications, while a smaller groups only searches once. In all five segments, a small fraction of the workers applies to many (i.e. 30) vacancies. The average number of applicants per vacancy varies between 2.3 and 3.3. This results in a job offer probability between 0.29 and 0.39, implying that most workers get either zero or one job offer.

We find that both the productivity of a match $y$ and the capital cost $k$ are monotonically increasing across the segments. The net productivity $y-k$ is also increasing, except between segment 2 and 3 , but the difference is only 0.8 and not statistically significant. The net output produced by a filled vacancy is 17.68 euros per hour in segment 1 and increases to 39.54 euros per hour in segment 5 . This is approximately 2 to 2.5 times the average wage in each segment, implying that firms capture a considerable part of the total output. The estimate for the unemployment benefits $b$ ranges from 3.60 euros per hour in the lowest segment to 6.26 euros per hour in the highest segment. We find that the legal minimum wage is binding in the two lowest segments, but not in the other three. Hence, in these latter three segments we can identify the reservation wage and obtain an estimate for $h$, the combined value of home production and utility derived from leisure. It turns out that $h$ is an important component of the reservation wage. The estimates are between 6.02 and 6.32 euros per hour, which corresponds to $60-80 \%$ of the reservation wage. For segments 1 and 2, we can only identify an upper bound on the value of home production.

The estimated match probability $m_{W}$ for a worker is lowest in segment 1 (0.036) and highest in segment $5(0.075)$. For the job destruction rate, we find the opposite pattern. It is highest in segment 1 , where a fraction 0.039 of the matches gets destroyed in each period, and monotonically decreases as we move to higher segments, being 0.011 in segment 5 . Note that these are the matching probabilities per period. If we convert them to annual values, we get matching probabilities between 0.101 and 0.205 and separation rates between 0.029 and $0.110 .^{13}$ These values seem very reasonable. They are of the same order of magnitude as

\footnotetext{
${ }^{13}$ As discussed in section 4, we assume that a year consists of three periods. This implies that a worker can flow from employment in year $\tau$ (time $t$ ) to non-employment in year $\tau+1$ (time $t+3$ ) in four different ways. She can loose her job at the beginning of either period $t+1, t+2$ or $t+3$, and remain non-employed after that. Alternatively, she can loose her job at $t+1$, get a new job at $t+2$ and loose it again at $t+3$. Hence, the yearly separation rate $\delta_{W, 3}$ for the workers is given by

$$
\begin{aligned}
\delta_{W, 3} & =\delta\left(1-m_{W}\right)^{2}+(1-\delta) \delta\left(1-m_{W}\right)+(1-\delta)^{2} \delta+\delta m_{W} \delta \\
& =\delta\left(\delta^{2}+m_{W}^{2}+2 \delta m_{W}-3 \delta-3 m_{W}+3\right) .
\end{aligned}
$$

Expressions for the yearly separation rate of firms $\left(\delta_{F, 3}\right)$ and the annual matching probability for workers $\left(m_{W, 3}\right)$ and firms $\left(m_{F, 3}\right)$ can be derived in a similar way.
} 
the ones reported by Davis and Haltiwanger (1999) for a selection of countries.

For firms we estimate matching probabilities between 0.613 and 0.715 . These values are in line with the matching probability given by Van Ours and Ridder (1992). Using Dutch survey data, they find that 71 percent of the reported vacancies had been filled four months later. Den Haan, Ramey and Watson (2000) find exactly the same value (but on a quarterly basis) for the US labor market. These high values can be explained by the fact that there are many more workers than jobs in the market, which makes it relatively easier for firms to match. The estimates imply yearly matching rates between 0.904 and 0.958 and separation rates between 0.016 and 0.057 .

Maximization of the likelihood also provides us with an estimate for the density of accepted wages $g_{w}(w)$. This estimate can be used to calculate the expected wage $E_{G_{w}(w)}[w]$. The values obtained in this way are also displayed in table 5 . They are very close to the values found in the data, which were presented in table 3. The expected wage offer $E_{F_{w}(w)}[w]$ is always slightly lower, reflecting the fact that lower wage offers are less likely to be accepted than higher ones. Figure 3 provides a closer look at the fit of the model. There we compare the estimate for $g_{\widetilde{w}}(\widetilde{w})$ to a kernel estimate of the wage density. ${ }^{14}$ The figure shows that our model indeed provides a very good fit to the data.

In order to determine to what extent the good fit depends on the presence of measurement error, we judge the estimates for the standard deviation $\sigma$. We find values between 0.007 (segment 2) and 0.074 (segment 5 ). The somewhat higher estimate of $\sigma$ in segment 5 is in line with the fact that more heterogeneity was still present there. However, in general we can conclude that the degree of measurement error is small. The estimates for $\sigma$ are of the same order of magnitude as the values found by Van den Berg and Ridder (1998), who find standard deviations of 0.022 and 0.045 . Moreover, they are considerably lower than the estimates of Dey and Flinn (2005). They find in various specifications of their model that $\sigma$ approximately equals 0.55. They argue that the degree of measurement error that is required to provide a good fit of the model to the data can be considered to be an index of the degree of model misspecification. Such being the case, we conclude that our model gives an adequate description of the labor market.

For all segments, we find that the densities of accepted wages are hump shaped (also if we estimate the model without measurement error). In this respect our model differs from the models described by, for example, Burdett and Mortensen (1998) and Gautier and Moraga-González (2004). Their models exclusively predict upward sloping densities. Another interesting result is that the wage distribution in each segment first-order stochastically dominates the distributions in all lower segments. Note that this was not directly visible in the raw data, where the lowest wages in the third segment were lower than in the second segment. By retrieving the true wage distribution, our model reveals that this is only the result of measurement error. In figure 4 we present the estimates for the search cost distributions. We find that search costs (measured in the same unit as the wages and the productivity) are in general higher in higher segments.

\footnotetext{
${ }^{14}$ We use a standard normal kernel with bandwith $1.06 s_{w} n^{-1 / 5}$, where $s_{w}$ denotes the standard deviation of $w$.
} 


\subsection{Mean-min ratio}

In a recent paper Hornstein, Krusell and Violante (2006, hereafter HKV) discuss a specific measure of wage dispersion, which is defined as the ratio between the average wage and the lowest wage paid to employed workers. They show that a closed form expression for this mean-min ratio $(\mathrm{Mm})$ can be obtained in a general class of search and matching models, without making any parametric assumption on the wage offer distribution. As defined before, $\rho$ denotes the replacement rate, i.e. the ratio between $b$ and the average wage. Then $M m$ is given by

$$
M m=\frac{1+\frac{m_{W}}{r+\delta}}{\rho+\frac{m_{W}}{r+\delta}} .
$$

Calibrating the model with US data on $m_{W}$ and $\delta$ results in $M m=1.036$. However, HKV find that in US data sets with wage information the ratio between the average wage and the reservation wage is typically about 1.70 or larger. From this, they conclude that standard search models are not able to explain the observed combination of a low reservation wage and a high matching rate for unemployed workers. A similar point was made in Gautier and Teulings (2006) who focus on the ratio of the highest and the reservation wage.

We set $m_{W}$ and $\delta$ at the estimated values that we obtained in the previous subsection, while keeping $\rho$ at 0.4 and $r$ at 0.016 . Then, we calculate the mean-min ratio as predicted by the market equilibrium and we compare this to what we observe in the data. The results of this are given in table 6 . If we follow HKV by taking the fifth percentile of the wage distribution $\left(w_{5 \%}\right)$ in each segment as the reservation wage, then the mean-min ratio in the data varies between 1.215 (segment 1) and 1.598 (segment 5). ${ }^{15}$ Note that our model differs in one important respect from the standard search models that they discuss. We do not only consider unemployed and employed workers, but we also allow workers to draw a high search cost so that it is optimal to become a non-participant. This matters for the matching probability. If we ignore the non-participants, we find that the matching probability $m_{W}^{U}=\frac{m_{W}}{1-p_{0}}$ is between 0.4 and 0.5 per period. This implies a mean-min ratio $M m^{U}$ that varies between 1.037 (segment 5) and 1.073 (segment 1). Those values are very close to the one found by HKV.

However, in our model, the unemployed workers are a selective subsample of the total group of nonemployed workers, namely the ones who happened to draw a low search cost in the current period and therefore have a large probability to receive a job offer in this period. They realize that in the next period they may draw a high search cost and they take this into account when they determine their reservation wage. We find that the mean-min ratio for the entire group of non-employed workers, $M m^{N E}$, is between 1.190 (segment 5) and 1.572 (segment 1). Hence, in our model where workers have a positive probability to become a non participant in the next period, a much larger part of the wage dispersion can be explained by search frictions. The possibility of becoming non-participant and consequently obtaining a very low matching rate in the next period is consistent with a low reservation wage and a high transition rate from unemployment to employment.

\footnotetext{
${ }^{15}$ For optimal comparison with HKV, we do not throw away outliers here.
} 


\subsection{Efficiency}

In order to check whether the Dutch labor market is constrained efficient we solve the planner's problem for each of the five segments. We use the estimates for the search cost distribution $F_{c}(c)$, the productivity $y$, the capital cost $k$ and the home productivity $h$ that we obtained above and maximize equation (33). We do this for each of the three cases described in section 3 (minimum, linear, maximum) and in the lowest two segments for both the lower and the upper bound of household production $h$.

Note that in general there is no trivial answer to the question whether the number of applications sent by workers in the market equilibrium is too high or too low from a social planner's point of view. Workers might underinvest in search since they face a standard hold-up problem. They only receive a part of the social benefits of their investments in search and therefore too many workers with high search cost may decide not to send applications. On the other hand however, workers could also send too many applications, since they only take into account their own expected payoff but ignore that applying more often increases the coordination frictions for all other agents in the market: if workers send multiple applications, several firms might offer the job to the same worker, implying that all except one remain unmatched. What about firm behavior? Albrecht et al. (2006) show that when all workers search two or more times efficient entry requires full ex ante and full ex post (i.e. Bertrand) competition for workers. This is not the case in our model. There is no full ex ante competition, since the firm that offers the lowest wage in the market receives as many applications as the other firms, and there is no full ex post competition, because a firm that offers the job to a worker with (an) other offer(s) still has a positive expected payoff. So, firms have too much market power making wages too low and entry excessive. If, most workers search only once, as is the case here, vacancy supply can be either too high or too low because of the standard congestion externalities. Opening a vacancy is good for the workers but bad for the other firms. If the planner can jointly determine $a(c)$ and the number of firms, he typically increases both vacancy supply and the number of participants. But for the reasons mentioned above, we find that if we impose the planner's participation level to the market, there would be too many vacancies opened in the market.

Table 7 presents the key parameters of the planner's solution for each of the segments. Focussing on the linear case, it turns out that three important differences exist between the market equilibrium and the planner's strategy. First, the planner wants a higher number of firms to enter the labor market. The increase in entry is relatively small (8\%) in segment 5 , but amounts to $55 \%$ in segment 1 . Second, the planner increases participation since he internalizes the hold-up problem: a considerable group of non-employed workers (11\%$30 \%$ ) must search once rather than zero times. Finally, the planner decreases the number of workers sending two or more applications. These workers (3\%-10\% of the non-employed) have low search costs, which makes it profitable for them to send so many applications. As described above however, they do not to take into account that their large number of applications increases the probability that multiple firms consider the same candidate, which is socially wasteful. Therefore, it is better if they apply only once per period. The minimum and the maximum case are bounds to this solution, not only in terms of total output, but also in 
terms of strategies. In the minimum case, the planner keeps $p_{0}$ equal to the value in the market equilibrium (since all non-participants have infinite search cost) and he changes the number of firms in the market only marginally. In the maximum case on the other hand, all non-employed are assumed to have only a marginally higher search cost then the ones who currently search. Then it is optimal to let everybody search once $\left(p_{1}=1\right)$. The number of active firms is now even higher than in the linear case.

Figure 5 displays the effects of these changes in strategy on steady state employment, non-participation, and unemployment. It shows that implementation of the planner's solution would typically increase the employment rate, decrease the non-participation and increase the unemployment rate. The increase in unemployment is a direct effect of a higher participation rate: when more workers search for a job, also a larger number will fail to find one. In line with the planner's strategy, the optimal level of non-participation depends on the assumption made for the right tail of the search cost distribution. In the minimum case, the optimal non-participation rate does not differ too much from what is observed in the market equilibrium. In the linear case, it is considerably lower, while in the maximum case it equals 0 for all segments.

Finally, table 7 reports the output per period for both the market equilibrium and the planner's solution. We define the efficiency of the labor market as the ratio of these two values. It turns out that the labor market is fully efficient in none of the segments. On average, the level of inefficiency equals approximately $15 \%$ in the linear case (ranging from $12 \%$ in segment 5 to $21 \%$ in segment 1 ). The two extreme cases provide reasonably narrow bounds on this value.

It is important to stress that the inefficiency results largely depends on the interaction between participation of workers and entry of firms. If we would keep either search intensity or the number of firms constant and let the planner optimize over the other factor, then it turns out that the planner can hardly do better than the market (differences are in the order of 1\%). The reason for this is that participation and firm's entry are complementary. A larger number of active firms encourages workers' participation, which, in turn, makes it more attractive for firms to enter. This implies that when one wants to estimate the effect of, for example, an active labor market program, it is crucial to take both factors into account. Otherwise, one will severely underestimate the true effects of the program. This also suggests that the common practice in the program evaluation literature to study the effects of policy changes in isolation can be very restrictive.

Our efficiency results also shed new light on the desirability of a binding but moderate minimum wage. It has the potential to reduce all three externalities that are present in our model. First, by increasing the average wage it makes more workers search once rather than zero times, increasing participation. Second, by compressing the wage distribution it reduces the incentives to search more than once, decreasing rent seeking behavior and coordination frictions. Third, it reduces monopsony power and excessive entry of vacancies. Unemployment benefits that are conditional on searching at least once have similar effects. As was shown in (16) they increase the marginal gain $\Gamma_{1}$ of the first application, but decrease the marginal gains of all following applications. $\Gamma_{2}$ decreases most relative to the case without UI benefits. 


\section{Related literature}

In this section we relate our paper to the existing literature. First, our model is very similar to the noisy search model of Burdett and Judd (1983) where search cost is a random variable. Albrecht and Axell (1984) also get wage dispersion due to worker heterogeneity. Their heterogeneity is in terms of reservation wages while ours is in terms of search costs which gives us a continuous rather than a discrete wage distribution. Bontemps, Robin and Van den Berg (2000), Bowles, Kiefer and Neumann (1995) and Mortensen (2003) focus on heterogeneity on the firm side. Bontemps, Robin and Van den Berg (1999) have heterogeneity on both the worker and firm side. Introducing firm heterogeneity in the Burdett-Mortensen (1998) model of on-the-job search gives a good fit of the wage distribution. All the introduced heterogeneity in the above mentioned papers is motivated by the fact that wage data do not fit the mixed-strategy wage distributions implied by the models. Burdett and Mortensen (1998), Burdett and Judd (1983) and Gautier and Moraga-González (2004) all have an increasing density. We show that simply allowing for heterogeneity in search cost gives a very good fit of the wage distribution. Basically, the fat right tail within a segment suggests that there is a small fraction of workers with low search cost, receiving many offers.

There are various models with endogenous search intensity. Benhabib and Bull (1983) consider the optimal number of applications in a partial search model with an exogenous wage distribution where, as in our model, workers take the highest offer. In Mortensen (1986), workers can increase the job offer arrival rate by spending more time on search. Bloemen (2005) estimates this model. Christensen et al. (2005) estimate a wage posting model where workers can make investments to increase the job offer arrival rate. The congestion effects of multiple applications that are present in our model are absent in their model. Albrecht et al. (2004) derive a matching function with multiple applications. More applications make it less likely that a vacancy has no applicants but more likely that multiple firms consider the same candidate. ${ }^{16}$ The matching rate is determined by the interaction between those coordination frictions. The aggregate matching function is typically first increasing and then decreasing in average search intensity. This paper extends this matching framework by allowing for heterogeneity in search cost and is the first one which estimates it simultaneously with the wage distribution. This is extremely important for policy analysis because wage policies affect search intensity and policies that affect search intensity will also affect the wage distribution.

There are many other structural estimates of search models, we mention just a few. Besides the ones mentioned above, Eckstein and Wolpin (1990) have estimated the Albrecht-Axell model, Van den Berg and Ridder (1998) estimate the Burdett-Mortensen model and Postel-Vinay and Robin (2004) estimate an onthe-job search model with Bertrand competition between the poaching and the incumbent firm. To our knowledge, there does not exist previous work estimating a labor market version of the Burdett and Judd (1983) model with rationing as in Gautier and Moraga-González (2004), as we do here.

There is a large microeconometric literature that studies the effect of actively counselling and monitoring

\footnotetext{
${ }^{16}$ In current work, it has become standard to define search intensity by the number of simultaneous job applications workers send out, see Albrecht, Gautier and Vroman (2003, 2006), Gautier and Moraga-González (2004), Gautier and Wolthoff (2006), Galenianos and Kircher (2005), Kircher (2006), Shimer (2004), Chade and Smith (2006).
} 
non-employed workers but it typically does not take into account the general equilibrium effects. Van den Berg and Van der Klaauw (2006) use a controlled social experiment in the Netherlands to show that the partial effects of counselling are small. Similarly, Ashenfelter, Ashmore and Deschênes (2005) and most of the papers discussed by Heckman, LaLonde and Smith (1999) find small effects of counselling and monitoring for the US. Gorter and Kalb (1996) find positive effects of intensive counselling with a group of workers with low expected labor market outcomes and Abbring, Van den Berg and Van Ours (2005) find that these workers are more likely to receive cuts in UI benefits because they do not search at all. Those sanctions do then decrease expected unemployment duration. In our framework those findings can be explained by the fact that the incremental gains from an extra job application are decreasing in the number of applications, i.e., the gains from moving from zero to one application are larger than from moving from $n>1$ to $n+1$ applications.

Finally, there are a couple of other papers that study the general equilibrium effects of labor market policies that increase search intensity. Flinn (2006) estimates a matching model with Nash bargaining and finds potential positive welfare effects of a binding minimum wage. Davidson and Woodbury (1993) and Blundell, Costa Dias and Meghir (2003) study the general equilibrium effects of giving a subset of workers a wage bonus our subsidy. Both find huge offsetting equilibrium effects and the latter even find a sign reversal since jobs taken by the treatment group would in the absence of the treatment be filled by non-treated workers. Lise, Seitz and Smith (2003) calibrate their equilibrium search model to data from the control group and then simulate a Canadian income assistance program within the model. They show that the model mimics the transition rate of the treatment group but that the total welfare effects are reversed when the general equilibrium effects are taken into account. A similar methodology is applied in Todd and Wolpin (2003). Our focus is not so much on the general equilibrium effects of specific programs, we estimate the equilibrium model from the beginning and then compare the optimal search intensity distribution with the observed one and find that they are pretty close. Given that observation, the general equilibrium welfare effects of a given small scale program are likely to be small.

\section{Final remarks}

We have presented a structural estimation of the search cost distribution and the implied search intensity of workers. Unlike most of the literature, we have explicitly defined the search intensity as the number of applications that workers send out per period. The model was estimated by maximum likelihood using wages of newly hired workers. We find that in all segments most unemployed workers search once or twice per four months while a small fraction of the searchers (between 0.5 and 1\%) applies to thirty jobs. We also show that the decentralized market outcome is surprisingly close to the constraint planner's outcome who takes the coordination frictions, value of home production, productivity and the search cost distribution as given. It appears that the planner would like some workers to search less. Especially sending two or thirty times is socially wasteful. 
One important real world feature that we left out in the model is on-the-job search. A natural question is therefore how our results would change if we would allow for it. This depends how employed and unemployed workers compete. Since unemployed workers have an unattractive outside option firms would prefer to offer a wage conditional on previous labor market state if they could. In that case, allowing for on the job search would (i) decrease expected job duration and (ii) would increase our estimate for home production. (i) has a similar effect as increasing the match destruction rate $\delta$, which does not affect the estimates for the search fractions $p_{a}$, the job offer probability $\psi$, the productivity $y$, etc. It only changes the scale of the search cost distribution and (ii) is caused by the fact that the option value of search when unemployed relative to search when employed goes down. In order for the reservation wage to be equal to the lowest wage in the segment, $b$ would have to go up.

Compared to the other empirical equilibrium search models in the literature we modelled the matching process and search intensity with a lot more detail but in other respects our model is simpler. For example, since workers are ex ante identical, unemployment duration follows a geometrical distribution while in reality there typically is positive duration dependence. One way to get positive duration dependence in our framework is by assuming the heterogeneity in search cost to be worker specific so that high-search-cost workers receive fewer offers in each period in expectation.

An interesting feature of our model is that by making a steady state assumption, the dynamic model can be estimated with cross section data which are readily available. 


\section{References}

[1] Abbring, J.H., G.J. van den Berg and J.C. van Ours, 2005, The effect of unemployment insurance sanctions on the transition rate from unemployment to employment, Economic Journal, vol. 115(505), pp. 602-630.

[2] Albrecht, J.W. And B. Axell, 1984, An equilibrium model of search unemployment, Journal of Political Economy, vol. 92(5), pp. 824-840.

[3] Albrecht, J.W., P.A. Gautier, S. Tan and S.B. Vroman, 2004, Matching with multiple applications revisited, Economics Letters, vol. 84, pp. 311-314.

[4] Albrecht J.W., P.A. Gautier and S.B. Vroman, 2003, Matching with multiple applications, Economics Letters, vol. 78, pp. 67-70.

[5] Albrecht J.W., P.A. Gautier and S.B. Vroman, 2006, Equilibrium directed search with multiple applications, Review of Economic Studies, vol. 73, pp. 869-891.

[6] Ashenfelter, Ashmore and Deschênes, 2005, Do unemployment insurance recipients actively seek work? Randomized trials in four US States, Journal of Econometrics, vol. 125, pp. 53-75.

[7] Benhabib J. And C. Bull, 1983, Job search, the choice of intensity, Journal of Political Economy, vol. 91(5), pp. 747-764.

[8] Blundell, R., M. Costa Dias and C. Meghir, 2003, The impact of wage subsidies: a general equilibrium approach, mimeo, Institute for Fiscal Studies.

[9] Blackwell, D., 1965, Discounted dynamic programming, Annals of Mathematical Statistics, vol. 36(1), pp. 226-235.

[10] Bloemen, H.G., 2005, Job search, search intensity, and labor market transitions: an empirical analysis, Journal of Human Resources, vol. 40(1), pp. 231-269.

[11] Bontemps, C., J.M. Robin and G.J. van den Berg, 1999, An empirical equilibrium job search model with search on the job and heterogeneous workers and firms, International Economic Review, vol. 40(4), pp. 1039-1074.

[12] Bontemps, C., J.M. Robin and G.J. van den Berg, 2000, Equilibrium search with continuous productivity dispersion: Theory and non-parametric estimation, International Economic Review, vol. 41(2), pp. 305-358.

[13] Bowles, A.J., N.M. Kiefer and G.R. Neumann, 1995, Estimation of equilibrium wage distributions with heterogeneity, Journal of Applied Econometrics, vol. 10, pp. S119-S131. 
[14] Burdett, K. And K.L. Judd, 1983, Equilibrium price dispersion, Econometrica, vol. 51(4), pp. 955969.

[15] Burdett, K. And D.T. Mortensen, 1998, Wage differential, employer size, and unemployment, International Economic Review, vol. 39(2), pp. 257-273.

[16] Christensen, B.J., R. Lentz, D.T. Mortensen, G.R. Neumann, and A. Wervatz, 2005, Onthe-job search and the wage distribution, Journal of Labor Economics, vol. 23(1), pp. 31-58.

[17] Chade, H. And L. Smith, 2006, Simultaneous search, Econometrica, vol. 74(5), pp. 1293-1307.

[18] Davidson, C. And S.A. Woodbury, 1993, The displacement effect of reemployment bonus programs, Journal of Labor Economics, vol. 11, pp. 575-605.

[19] Davis, S.J. and J. Haltiwanger, 1999, Gross job flows, Handbook of Labor Economics, vol. 3, O. Ashenfelter and D. Card, eds., North Holland, Amsterdam.

[20] Den Haan, W.J., G. Ramey and J. Watson, 2000, Job destruction and propagation shocks, American Economic Review, vol. 90(3), pp. 482-498.

[21] Dey, M.S. And C.J. Flinn, 2005, An equilibrium model of health insurance provision and wage determination, Econometrica, vol. 73(2), pp. 571-627.

[22] Diamond, P., 1971, A model of price adjustment, Journal of Economic Theory, vol. 3, pp. 156-168.

[23] Donald, S.G. And H.J. PaArsch, 1993, Piecewise pseudo-maximum likelihood estimation in empirical models of auctions, International Economic Review, vol. 34, pp. 121-148.

[24] Eckstein, Z. and K.I. Wolpin, 1990, Estimating an equilibrium search model using longitudinal data on individuals, Econometrica, vol. 58, pp. 783-808

[25] Flinn, C.J., 2006, Minimum wage effects on labor market outcomes under search, matching, and endogenous contact rates, Econometrica, vol. 74(4), pp. 1013-1062.

[26] Galenianos, M. And P. Kircher, 2005, Directed search with multiple job applications, PIER working paper 05-022, Penn Institute for Economic Research.

[27] Gautier, P.A. And J.L. Moraga-Gonzalez, 2004, Strategic wage setting and random search with multiple applications, Tinbergen Institute discussion paper 04-063/1, Tinbergen Institute.

[28] Gautier, P.A. And C.N. Teulings, 2006, How large are search frictions?, Journal of the European Economic Association, vol. 4(6), pp. 1193-1225.

[29] Gautier, P.A. and R.P. Wolthoff, 2006, Simultaneous search with heterogeneous firms and ex post competition, Tinbergen Institute discussion paper 06-032/3, Tinbergen Institute. 
[30] Gorter, C and G.R.J. Kalb, 1996, Estimating the effect of counseling and monitoring the unemployed using a job search model, Journal of Human Resources, vol. 31, pp. 590-610.

[31] Graham, J.W. and A.H. Beller, 1989, The effect of child support payments on the labor supply of female family heads, Journal of Human Resources, vol. 24(4), pp. 664-688.

[32] Heckman J.J, 1974, The effect of child-care programs on women's work effort, Journal of Political Economy, vol. 82, pp. 153-161.

[33] Heckman, J.J., R.J. LaLonde and J.A. Smith, 1999, The economics and econometrics of active labor market programs, Handbook of Labor Economics, vol. 3, O. Ashenfelter and D. Card, eds., North Holland, Amsterdam.

[34] Hornstein, A., P. Krusell and G.L. Violante, 2006, Frictional wage dispersion in search models: a quantitative approach, CEPR discussion paper 5935, CEPR.

[35] Kiefer, N.M. and G.R. Neumann, 1993, Wage dispersion with homogeneity: the empirical equilibrium search model, Panel Data and Labour Market Dynamics, H. Bunzel et al., eds., North Holland, Amsterdam.

[36] KIrcher, P., 2006, Simultaneous directed search with recall, mimeo, University of Bonn.

[37] Lise, J., S. Seitz And J. Smith, 2003, Equilibrium policy experiments and the evaluation of social programs, mimeo.

[38] Moraga-Gonzalez, J.L. And M.R. Wildenbeest, 2006, Maximum likelihood estimation of search costs, Tinbergen Institute discussion paper 06-019/1, Tinbergen Institute.

[39] Mortensen, D.T., 1986, Job search and labor market analysis, Handbook of Labor Economics, O. Ashenfelter and R. Layard, eds., North Holland, Amsterdam.

[40] Mortensen, D.T., 2003, Wage dispersion: why are similar workers paid differently?, MIT Press, Cambridge.

[41] Postel-Vinay, F. And J.-M. Robin, 2004, To match or not to match? Optimal wage policy with endogenous worker search intensity, Review of Economic Dynamics, vol. 7(2), pp. 297-331.

[42] Shimer, R., 2004, Search intensity, mimeo, University of Chicago.

[43] Teulings, C.N. And P.A. Gautier, 2004, The right man for the job, Review of Economic Studies, vol. 71(2), pp. 553-580.

[44] Todd, P. And K. Wolpin, 2003, Using experimental data to validate a dynamic behavior model of child schooling on fertility, mimeo, University of Pennsylvania. 
[45] Van den Berg, G.J. and B. van der Klaauw, 2006, Counseling and monitoring of unemployed workers: theory and evidence from a controlled social experiment, International Economic Review, vol. 47(3), pp. 895-936.

[46] Van den Berg, G.J. And G. Ridder, 1998, An empirical equilibrium search model of the labor market, Econometrica, vol. 66, pp. 1183-1221.

[47] Van Ours, J.C. And G. Ridder, 1992, Vacancies and the recruitment of new employees, Journal of Labor Economics, vol. 10(2), pp. 138-155.

[48] Van Ours, J.C. And G. Ridder, 1993, Vacancy durations: search or selection?, Oxford Bulletin of Economics and Statistics, vol. 55(2), pp. 187-198.

[49] Venema, P.M. and A. Faas and J.A. Samadhan, 2003, Arbeidsvoorwaardenontwikkelingen in 2002 (in Dutch), Arbeidsinspectie, The Hague. 


\section{Appendix}

\section{A Tables and figures}

\begin{tabular}{|c|c|c|c|c|c|c|c|}
\hline Variable & Estimate & Std.err. & & Variable & Estimate & Std.err. & \\
\hline \multirow[t]{2}{*}{ Constant } & 1.192 & 0.116 & * & Year & & & \\
\hline & & & & 1997 & -0.012 & 0.015 & \\
\hline Education & & & & 1998 & 0.010 & 0.014 & \\
\hline \multirow[t]{2}{*}{ Years of education } & 0.075 & 0.008 & * & 2000 & 0.054 & 0.014 & $*$ \\
\hline & & & & 2001 & 0.036 & 0.015 & $*$ \\
\hline Gender & & & & 2002 & 0.041 & 0.016 & $*$ \\
\hline \multirow[t]{2}{*}{ Male } & -0.047 & 0.032 & & & & & \\
\hline & & & & Interaction effects & & & \\
\hline Experience & & & & Educ. $\times$ Experience & -0.110 & 0.066 & \\
\hline Experience & 3.792 & 0.930 & * & Educ. $\times$ Experience $^{2}$ & 0.404 & 0.183 & * \\
\hline Experience $^{2}$ & -9.955 & 2.283 & * & Educ. $\times$ Experience $^{3}$ & -0.378 & 0.156 & * \\
\hline \multirow[t]{2}{*}{ Experience $^{3}$} & 7.805 & 1.733 & $*$ & Male $\times$ Experience & 0.349 & 0.355 & \\
\hline & & & & Male $\times$ Experience $^{2}$ & 0.790 & 1.016 & \\
\hline Statistics & & & & Male $\times$ Experience ${ }^{3}$ & -1.343 & 0.817 & \\
\hline Observations & 5801 & & & & & & \\
\hline $\mathrm{R}^{2}$ & 0.358 & & & & & & \\
\hline
\end{tabular}

Table 1: Estimation results of the skill regression 


\begin{tabular}{|c|c|c|c|c|c|c|c|}
\hline Variable & Estimate & Std.err. & & Variable & Estimate & Std.err. & \\
\hline \multirow[t]{2}{*}{ Constant } & 2.251 & 0.023 & $*$ & Job level & & & \\
\hline & & & & Level 2 & 0.027 & 0.014 & * \\
\hline Sector & & & & Level 3 & 0.166 & 0.014 & * \\
\hline Industry & -0.026 & 0.019 & & Level 4 & 0.327 & 0.016 & * \\
\hline Education & -0.013 & 0.028 & & Level 5 & 0.570 & 0.023 & * \\
\hline Construction & 0.133 & 0.022 & * & Level 6-8 & 0.743 & 0.046 & * \\
\hline Trade, reparation & -0.052 & 0.021 & * & & & & \\
\hline Hotel, catering & 0.055 & 0.031 & & Occupation type & & & \\
\hline Transport, communic. & -0.049 & 0.023 & * & Administrative & -0.031 & 0.012 & * \\
\hline Financial services & -0.001 & 0.031 & & Automation & -0.022 & 0.021 & \\
\hline Other services & -0.064 & 0.022 & * & Commercial & -0.029 & 0.015 & * \\
\hline Health care & 0.007 & 0.026 & & Service providing & -0.062 & 0.011 & * \\
\hline \multirow[t]{2}{*}{ Culture, recreation } & -0.052 & 0.036 & * & Creative & -0.021 & 0.031 & \\
\hline & & & & Management & 0.193 & 0.039 & * \\
\hline \multicolumn{8}{|l|}{ Year } \\
\hline 1997 & -0.025 & 0.013 & & Coll. empl. agree & ment (CAO) & & \\
\hline 1998 & 0.001 & 0.013 & & AVV & 0.081 & 0.015 & * \\
\hline 2000 & 0.023 & 0.013 & & Company CAO & -0.047 & 0.019 & * \\
\hline 2001 & 0.014 & 0.013 & & No CAO & -0.052 & 0.010 & * \\
\hline 2002 & 0.051 & 0.015 & * & & & & \\
\hline \multicolumn{8}{|l|}{ Statistics } \\
\hline Observations & 5801 & & & & & & \\
\hline $\mathrm{R}^{2}$ & 0.475 & & & & & & \\
\hline
\end{tabular}

Table 2: Estimation results of the complexity regression

\begin{tabular}{lrrrrr}
\hline & $\mathbf{1}$ & $\mathbf{2}$ & $\mathbf{3}$ & $\mathbf{4}$ & $\mathbf{5}$ \\
\hline Labor market states & & & & & \\
Employment $(e)$ & 0.479 & 0.615 & 0.736 & 0.790 & 0.875 \\
Unemployment $(u)$ & 0.043 & 0.033 & 0.030 & 0.027 & 0.022 \\
Non-participation $(n)$ & 0.477 & 0.351 & 0.234 & 0.183 & 0.103 \\
& & & & & \\
Vacancies & & & & & \\
Number of vacancies $\left(v N_{F}\right)$ & 0.030 & 0.023 & 0.021 & 0.019 & 0.015 \\
& & & & & \\
Non-participation & & & & & \\
Number of non-participants $\left(p_{0}\right)$ & 0.917 & 0.914 & 0.885 & 0.870 & 0.826 \\
& & & & & \\
Wage distribution & & & & & \\
Lowest observed wage & 7.40 & 7.42 & 7.36 & 8.08 & 9.46 \\
Highest observed wage & 12.07 & 14.08 & 15.17 & 16.81 & 27.25 \\
Mean observed wage & 9.00 & 10.07 & 10.73 & 12.17 & 15.75 \\
\hline
\end{tabular}

Table 3: Values of the exogenous parameters per segment 


\begin{tabular}{|c|c|c|c|c|c|c|c|c|c|c|}
\hline & \multicolumn{2}{|c|}{ Segment 1} & \multicolumn{2}{|c|}{ Segment 2} & \multicolumn{2}{|c|}{ Segment 3} & \multicolumn{2}{|c|}{ Segment 4} & \multicolumn{2}{|c|}{ Segment 5} \\
\hline & mean & s.d. & mean & s.d. & mean & s.d. & mean & s.d. & mean & s.d. \\
\hline Observations & 1043 & & 1179 & & 1153 & & 1070 & & 1022 & \\
\hline Male & 0.52 & 0.50 & 0.63 & 0.48 & 0.71 & 0.45 & 0.72 & 0.45 & 0.67 & 0.47 \\
\hline Education & 8.05 & 1.88 & 10.42 & 1.88 & 11.72 & 2.16 & 12.93 & 2.23 & 14.75 & 1.38 \\
\hline Age & 32.55 & 9.45 & 31.83 & 9.70 & 31.49 & 8.78 & 31.93 & 8.73 & 33.50 & 8.65 \\
\hline \multicolumn{11}{|l|}{ Sector } \\
\hline Agriculture & 0.02 & 0.12 & 0.03 & 0.18 & 0.03 & 0.18 & 0.02 & 0.13 & 0.02 & 0.14 \\
\hline Industry & 0.30 & 0.46 & 0.24 & 0.43 & 0.25 & 0.44 & 0.18 & 0.39 & 0.15 & 0.36 \\
\hline Education & 0.00 & 0.01 & 0.01 & 0.11 & 0.01 & 0.10 & 0.01 & 0.09 & 0.01 & 0.11 \\
\hline Construction & 0.01 & 0.12 & 0.03 & 0.16 & 0.07 & 0.26 & 0.21 & 0.40 & 0.09 & 0.29 \\
\hline Trade, reparation & 0.17 & 0.38 & 0.19 & 0.39 & 0.13 & 0.34 & 0.12 & 0.33 & 0.08 & 0.27 \\
\hline Hotel, catering & 0.04 & 0.20 & 0.04 & 0.19 & 0.03 & 0.18 & 0.02 & 0.15 & 0.01 & 0.10 \\
\hline Transp., communic. & 0.04 & 0.20 & 0.10 & 0.30 & 0.11 & 0.31 & 0.04 & 0.20 & 0.03 & 0.17 \\
\hline Financial services & 0.01 & 0.08 & 0.02 & 0.14 & 0.03 & 0.17 & 0.06 & 0.23 & 0.06 & 0.24 \\
\hline Other services & 0.27 & 0.45 & 0.19 & 0.39 & 0.23 & 0.42 & 0.22 & 0.42 & 0.37 & 0.48 \\
\hline Health care & 0.10 & 0.30 & 0.13 & 0.34 & 0.09 & 0.28 & 0.09 & 0.29 & 0.13 & 0.34 \\
\hline Culture, recreation & 0.03 & 0.18 & 0.02 & 0.13 & 0.01 & 0.11 & 0.02 & 0.14 & 0.04 & 0.19 \\
\hline \multicolumn{11}{|l|}{ Coll. empl. agr. } \\
\hline AVV & 0.03 & 0.16 & 0.05 & 0.22 & 0.06 & 0.25 & 0.09 & 0.29 & 0.09 & 0.29 \\
\hline Company CAO & 0.10 & 0.30 & 0.06 & 0.23 & 0.06 & 0.24 & 0.05 & 0.21 & 0.02 & 0.14 \\
\hline No CAO & 0.32 & 0.47 & 0.27 & 0.44 & 0.25 & 0.44 & 0.25 & 0.43 & 0.36 & 0.48 \\
\hline \multicolumn{11}{|l|}{ Firm size } \\
\hline 1-4 employees & 0.02 & 0.16 & 0.03 & 0.16 & 0.05 & 0.21 & 0.04 & 0.20 & 0.02 & 0.15 \\
\hline 5-9 employees & 0.08 & 0.27 & 0.06 & 0.24 & 0.11 & 0.31 & 0.09 & 0.29 & 0.09 & 0.29 \\
\hline 10-19 employees & 0.12 & 0.33 & 0.13 & 0.33 & 0.13 & 0.33 & 0.13 & 0.34 & 0.09 & 0.28 \\
\hline 20-49 employees & 0.22 & 0.42 & 0.18 & 0.38 & 0.17 & 0.37 & 0.21 & 0.41 & 0.12 & 0.33 \\
\hline 50-99 employees & 0.09 & 0.29 & 0.11 & 0.32 & 0.11 & 0.31 & 0.10 & 0.29 & 0.12 & 0.33 \\
\hline 100-199 employees & 0.10 & 0.31 & 0.13 & 0.34 & 0.12 & 0.33 & 0.09 & 0.28 & 0.09 & 0.28 \\
\hline 200-499 employees & 0.14 & 0.35 & 0.16 & 0.36 & 0.11 & 0.31 & 0.14 & 0.35 & 0.14 & 0.34 \\
\hline$\geq 500$ employees & 0.22 & 0.41 & 0.21 & 0.41 & 0.22 & 0.41 & 0.20 & 0.40 & 0.33 & 0.47 \\
\hline \multicolumn{11}{|l|}{ Job level } \\
\hline Level 1 & 0.21 & 0.41 & 0.02 & 0.14 & 0.01 & 0.11 & 0.00 & 0.02 & 0.00 & 0.00 \\
\hline Level 2 & 0.57 & 0.49 & 0.20 & 0.40 & 0.07 & 0.25 & 0.01 & 0.12 & 0.00 & 0.02 \\
\hline Level 3 & 0.21 & 0.41 & 0.76 & 0.43 & 0.75 & 0.43 & 0.45 & 0.50 & 0.09 & 0.29 \\
\hline Level 4 & 0.00 & 0.00 & 0.01 & 0.11 & 0.17 & 0.38 & 0.51 & 0.50 & 0.33 & 0.47 \\
\hline Level 5 & 0.00 & 0.00 & 0.00 & 0.00 & 0.00 & 0.00 & 0.02 & 0.15 & 0.44 & 0.50 \\
\hline Level 6-8 & 0.00 & 0.00 & 0.00 & 0.00 & 0.00 & 0.00 & 0.00 & 0.00 & 0.14 & 0.35 \\
\hline \multicolumn{11}{|c|}{ Nature of occupation } \\
\hline Simple techn. act. & 0.39 & 0.49 & 0.33 & 0.47 & 0.42 & 0.49 & 0.39 & 0.49 & 0.23 & 0.42 \\
\hline Administrative & 0.08 & 0.28 & 0.20 & 0.40 & 0.15 & 0.36 & 0.19 & 0.40 & 0.13 & 0.34 \\
\hline Automation & 0.01 & 0.08 & 0.01 & 0.10 & 0.03 & 0.16 & 0.05 & 0.22 & 0.08 & 0.27 \\
\hline Commercial & 0.06 & 0.24 & 0.08 & 0.27 & 0.11 & 0.31 & 0.12 & 0.33 & 0.10 & 0.31 \\
\hline Service providing & 0.46 & 0.50 & 0.38 & 0.48 & 0.29 & 0.45 & 0.19 & 0.40 & 0.25 & 0.43 \\
\hline Creative & 0.00 & 0.05 & 0.01 & 0.08 & 0.01 & 0.11 & 0.03 & 0.18 & 0.13 & 0.33 \\
\hline Management & 0.00 & 0.00 & 0.00 & 0.00 & 0.00 & 0.03 & 0.01 & 0.11 & 0.09 & 0.29 \\
\hline
\end{tabular}

Table 4: Descriptive statistics per segment 


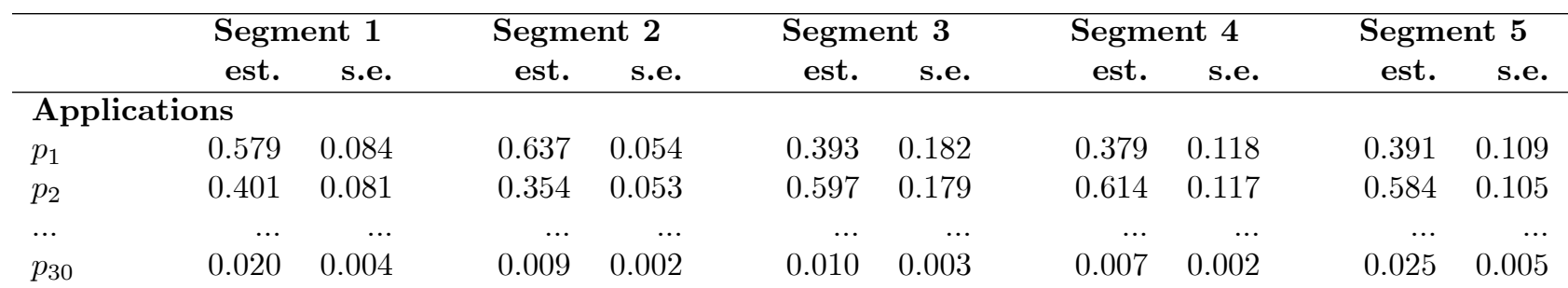

Other ML parameters

$\begin{array}{lrrrrrrrrrr}\widehat{y} & 17.68 & 0.89 & 26.96 & 1.50 & 26.15 & 2.04 & 30.70 & 1.72 & 39.54 & 2.72 \\ \underline{w} & 7.51 & 0.00 & 7.51 & 0.00 & 7.56 & 0.12 & 8.29 & 0.13 & 10.61 & 0.29 \\ \sigma & 0.012 & 0.005 & 0.007 & 0.003 & 0.031 & 0.012 & 0.026 & 0.013 & 0.074 & 0.016\end{array}$

Job offers

$\begin{array}{lrrrrrrrrrr}q_{0} & 0.565 & 0.012 & 0.520 & 0.006 & 0.512 & 0.006 & 0.499 & 0.004 & 0.571 & 0.012 \\ q_{1} & 0.371 & 0.017 & 0.417 & 0.010 & 0.406 & 0.012 & 0.416 & 0.007 & 0.355 & 0.014 \\ q_{2} & 0.044 & 0.003 & 0.054 & 0.004 & 0.072 & 0.006 & 0.077 & 0.005 & 0.049 & 0.004 \\ \ldots & \ldots & \ldots & \ldots & \ldots & \ldots & \ldots & \ldots & \ldots & \ldots & \ldots \\ q_{4} & 0.000 & 0.000 & 0.000 & 0.000 & 0.000 & 0.000 & 0.000 & 0.000 & 0.001 & 0.001 \\ q_{5} & 0.000 & 0.000 & 0.000 & 0.000 & 0.000 & 0.000 & 0.000 & 0.000 & 0.001 & 0.001 \\ q_{6} & 0.001 & 0.001 & 0.000 & 0.000 & 0.000 & 0.000 & 0.000 & 0.000 & 0.002 & 0.001 \\ q_{7} & 0.002 & 0.001 & 0.000 & 0.000 & 0.001 & 0.001 & 0.000 & 0.000 & 0.003 & 0.001 \\ q_{8} & 0.002 & 0.001 & 0.001 & 0.000 & 0.001 & 0.001 & 0.001 & 0.000 & 0.004 & 0.001 \\ q_{9} & 0.003 & 0.001 & 0.001 & 0.000 & 0.001 & 0.001 & 0.001 & 0.000 & 0.004 & 0.001 \\ q_{10} & 0.003 & 0.001 & 0.001 & 0.000 & 0.002 & 0.001 & 0.001 & 0.000 & 0.003 & 0.000 \\ q_{11} & 0.003 & 0.000 & 0.001 & 0.000 & 0.001 & 0.000 & 0.001 & 0.000 & 0.003 & 0.000 \\ q_{12} & 0.002 & 0.000 & 0.001 & 0.000 & 0.001 & 0.000 & 0.001 & 0.000 & 0.002 & 0.000 \\ q_{13} & 0.002 & 0.000 & 0.001 & 0.000 & 0.001 & 0.000 & 0.001 & 0.000 & 0.001 & 0.000 \\ q_{14} & 0.001 & 0.000 & 0.001 & 0.000 & 0.001 & 0.000 & 0.000 & 0.000 & 0.000 & 0.000 \\ q_{15} & 0.000 & 0.000 & 0.001 & 0.000 & 0.000 & 0.000 & 0.000 & 0.000 & 0.000 & 0.000\end{array}$

Transition probabilities

\begin{tabular}{lrrrrr}
$\delta$ & 0.039 & 0.026 & 0.020 & 0.017 & 0.011 \\
$m_{W}$ & 0.036 & 0.041 & 0.056 & 0.065 & 0.075 \\
$m_{F}$ & 0.622 & 0.686 & 0.697 & 0.715 & 0.613 \\
$\delta_{W, 3}$ & 0.110 & 0.073 & 0.056 & 0.048 & 0.029 \\
$\delta_{F, 3}$ & 0.057 & 0.036 & 0.027 & 0.023 & 0.016 \\
$m_{W, 3}$ & 0.101 & 0.116 & 0.156 & 0.179 & 0.931 \\
$m_{F, 3}$ & 0.904 & 0.940 & 0.950 & 0.958 & \\
\multicolumn{2}{l}{ Other variables } & & & & 3.313 \\
$\phi$ & 2.824 & 2.308 & 2.692 & 2.607 & 0.291 \\
$\psi$ & 0.333 & 0.390 & 0.346 & 0.355 & 6.26 \\
$b$ & 3.60 & 4.02 & 4.27 & 4.83 & 6.32 \\
$h$ & {$[0,6.99]$} & {$[0,6.64]$} & 6.02 & 6.04 & 541.31 \\
$k$ & 96.66 & 274.06 & 295.20 & 395.23 & 15.11 \\
$E_{F_{w}}[w]$ & 8.87 & 9.91 & 10.46 & 11.86 & 15.65 \\
$E_{G_{w}}[w]$ & 9.01 & 10.06 & 10.67 & 12.09 &
\end{tabular}

\section{Statistics}

$\begin{array}{lccccc}\text { Obs. } & 1043 & 1179 & 1153 & 1070 & 1022 \\ \text { LogL. } & -1.352 & -1.776 & -1.940 & -2.077 & -2.641\end{array}$

The presented fractions are conditional on searching at least once. The fraction of non-searchers $\left(p_{0}\right)$ is displayed in table 3. The not reported fractions are equal to (or rounded down to) zero for all segments.

Table 5: Estimation results 


\begin{tabular}{lrrrrr}
\hline & \multicolumn{5}{c}{ Segment } \\
& $\mathbf{1}$ & $\mathbf{2}$ & $\mathbf{3}$ & $\mathbf{4}$ & $\mathbf{5}$ \\
\hline Data & & & & & \\
$w_{\text {avg }}$ & 9.12 & 10.21 & 10.97 & 12.35 & 16.33 \\
$w_{1 \%}$ & 7.12 & 7.50 & 7.40 & 7.14 & 8.31 \\
$w_{2 \%}$ & 7.50 & 7.65 & 7.51 & 7.98 & 9.06 \\
$w_{5 \%}$ & 7.51 & 7.90 & 7.92 & 8.60 & 10.22 \\
$M p 1$ & 1.281 & 1.361 & 1.481 & 1.729 & 1.965 \\
$M p 2$ & 1.216 & 1.336 & 1.461 & 1.548 & 1.803 \\
$M p 5$ & 1.215 & 1.293 & 1.385 & 1.435 & 1.598 \\
& & & & & \\
Model & & & & & \\
$m_{W}^{N E}$ & 0.036 & 0.041 & 0.056 & 0.065 & 0.075 \\
$m_{W}^{U}$ & 0.435 & 0.480 & 0.488 & 0.501 & 0.429 \\
$\delta$ & 0.039 & 0.026 & 0.020 & 0.017 & 0.011 \\
$r$ & 0.016 & 0.016 & 0.016 & 0.016 & 0.016 \\
$\rho$ & 0.400 & 0.400 & 0.400 & 0.400 & 0.400 \\
$M m^{N E}$ & 1.572 & 1.435 & 1.310 & 1.258 & 1.190 \\
$M m^{U}$ & 1.073 & 1.051 & 1.044 & 1.039 & 1.037 \\
\hline
\end{tabular}

Table 6: Mean-min ratio in data and model 


\begin{tabular}{|c|c|c|c|c|c|c|c|c|c|}
\hline & \multirow[t]{2}{*}{ Market } & \multicolumn{3}{|c|}{ Planner } & & \multirow[t]{2}{*}{ Market } & \multicolumn{3}{|c|}{ Planner } \\
\hline & & $\min$ & linear & $\max$ & & & $\min$ & linear & $\max$ \\
\hline \multicolumn{5}{|c|}{ Segment $1(h=0)$} & \multicolumn{5}{|c|}{ Segment $1(h=6.99)$} \\
\hline$p_{0}$ & 0.917 & 0.917 & 0.807 & 0.000 & $p_{0}$ & 0.917 & 0.917 & 0.741 & 0.000 \\
\hline$p_{1}$ & 0.048 & 0.083 & 0.193 & 1.000 & $p_{1}$ & 0.048 & 0.083 & 0.259 & 1.000 \\
\hline$p_{2}$ & 0.033 & 0.000 & 0.000 & 0.000 & $p_{2}$ & 0.033 & 0.000 & 0.000 & 0.000 \\
\hline$\cdots$ & $\cdots$ & & $\cdots$ & & $\cdots$ & م000 & & & مחת \\
\hline$p_{30}$ & 0.002 & 0.000 & 0.000 & 0.000 & $p_{30}$ & 0.002 & 0.000 & 0.000 & 0.000 \\
\hline$N_{F}$ & 0.510 & 0.591 & 0.781 & 0.979 & $N_{F}$ & 0.510 & 0.537 & 0.790 & 0.951 \\
\hline Output & 5.10 & 5.54 & 6.47 & 8.65 & Output & 8.74 & 9.72 & 10.54 & 11.82 \\
\hline Efficiency & & 0.920 & 0.787 & 0.589 & Efficiency & & 0.899 & 0.829 & 0.739 \\
\hline \multicolumn{5}{|c|}{ Segment $2(h=0)$} & \multicolumn{5}{|c|}{ Segment $2(h=6.64)$} \\
\hline$p_{0}$ & 0.914 & 0.914 & 0.791 & 0.000 & $p_{0}$ & 0.914 & 0.914 & 0.690 & 0.000 \\
\hline$p_{1}$ & 0.055 & 0.086 & 0.209 & 1.000 & $p_{1}$ & 0.055 & 0.086 & 0.310 & 1.000 \\
\hline$p_{2}$ & 0.031 & 0.000 & 0.000 & 0.000 & $p_{2}$ & 0.031 & 0.000 & 0.000 & 0.000 \\
\hline$p_{30}$ & 0.001 & 0.000 & 0.000 & 0.000 & $p_{30}$ & 0.001 & 0.000 & 0.000 & 0.000 \\
\hline$N_{F}$ & 0.639 & 0.663 & 0.833 & 0.977 & $N_{F}$ & 0.639 & 0.633 & 0.864 & 0.962 \\
\hline Output & 9.42 & 9.68 & 11.05 & 13.70 & Output & 11.97 & 13.18 & 14.88 & 16.72 \\
\hline Efficiency & & 0.973 & 0.852 & 0.688 & Efficiency & & 0.908 & 0.804 & 0.716 \\
\hline \multicolumn{5}{|c|}{ Segment $3(h=6.02)$} & \multicolumn{5}{|c|}{ Segment $4(h=6.04)$} \\
\hline$p_{0}$ & 0.885 & 0.885 & 0.703 & 0.000 & $p_{0}$ & 0.870 & 0.870 & 0.688 & 0.000 \\
\hline$p_{1}$ & 0.045 & 0.115 & 0.297 & 1.000 & $p_{1}$ & 0.049 & 0.130 & 0.312 & 1.000 \\
\hline$p_{2}$ & 0.069 & 0.000 & 0.000 & 0.000 & $p_{2}$ & 0.080 & 0.000 & 0.000 & 0.000 \\
\hline$\cdots$ & $\begin{array}{r}\cdots \\
0.001\end{array}$ & $\begin{array}{r}\cdots \\
0.000\end{array}$ & 0.000 & $\begin{array}{c}\cdots \\
0.000\end{array}$ & $\cdots$ & $\cdots$ & $\cdots$ & $\begin{array}{ll}\cdots \\
0000\end{array}$ & $\ldots$ \\
\hline$N_{F}$ & 0.757 & 0.747 & 0.887 & 0.972 & $N_{F}$ & 0.809 & 0.793 & 0.905 & 0.975 \\
\hline Output & 13.54 & 14.77 & 15.83 & 17.37 & Output & 16.75 & 18.00 & 19.06 & 20.67 \\
\hline Efficiency & & 0.917 & 0.855 & 0.779 & Efficiency & & 0.931 & 0.879 & 0.811 \\
\hline \multicolumn{10}{|c|}{ Segment $5(h=6.32)$} \\
\hline$p_{0}$ & 0.826 & 0.826 & 0.522 & 0.000 & & & & & \\
\hline$p_{1}$ & 0.068 & 0.174 & 0.478 & 1.000 & & & & & \\
\hline$p_{2}$ & 0.101 & 0.000 & 0.000 & 0.000 & & & & & \\
\hline$\cdots$ & & & $\ldots$ & $\cdots$ & & & & & \\
\hline$p_{30}$ & 0.004 & 0.000 & 0.000 & 0.000 & & & & & \\
\hline$N_{F}$ & 0.890 & 0.895 & 0.962 & 0.985 & & & & & \\
\hline Output & 25.79 & 28.74 & 29.93 & 31.04 & & & & & \\
\hline Efficiency & & 0.897 & 0.862 & 0.831 & & & & & \\
\hline
\end{tabular}

Table 7: Planner's solution and efficiency 


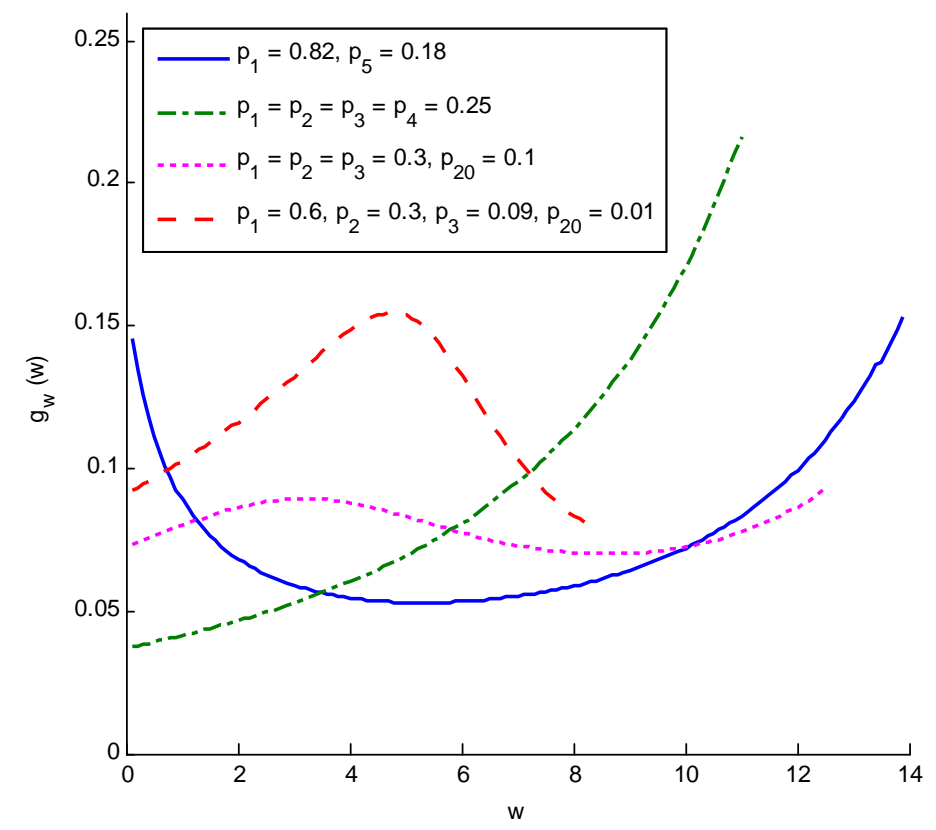

Figure 1: $g_{w}(w)$ for different values of the fractions $\left\{p_{0}, p_{1}, \ldots, p_{S}\right\}$ 

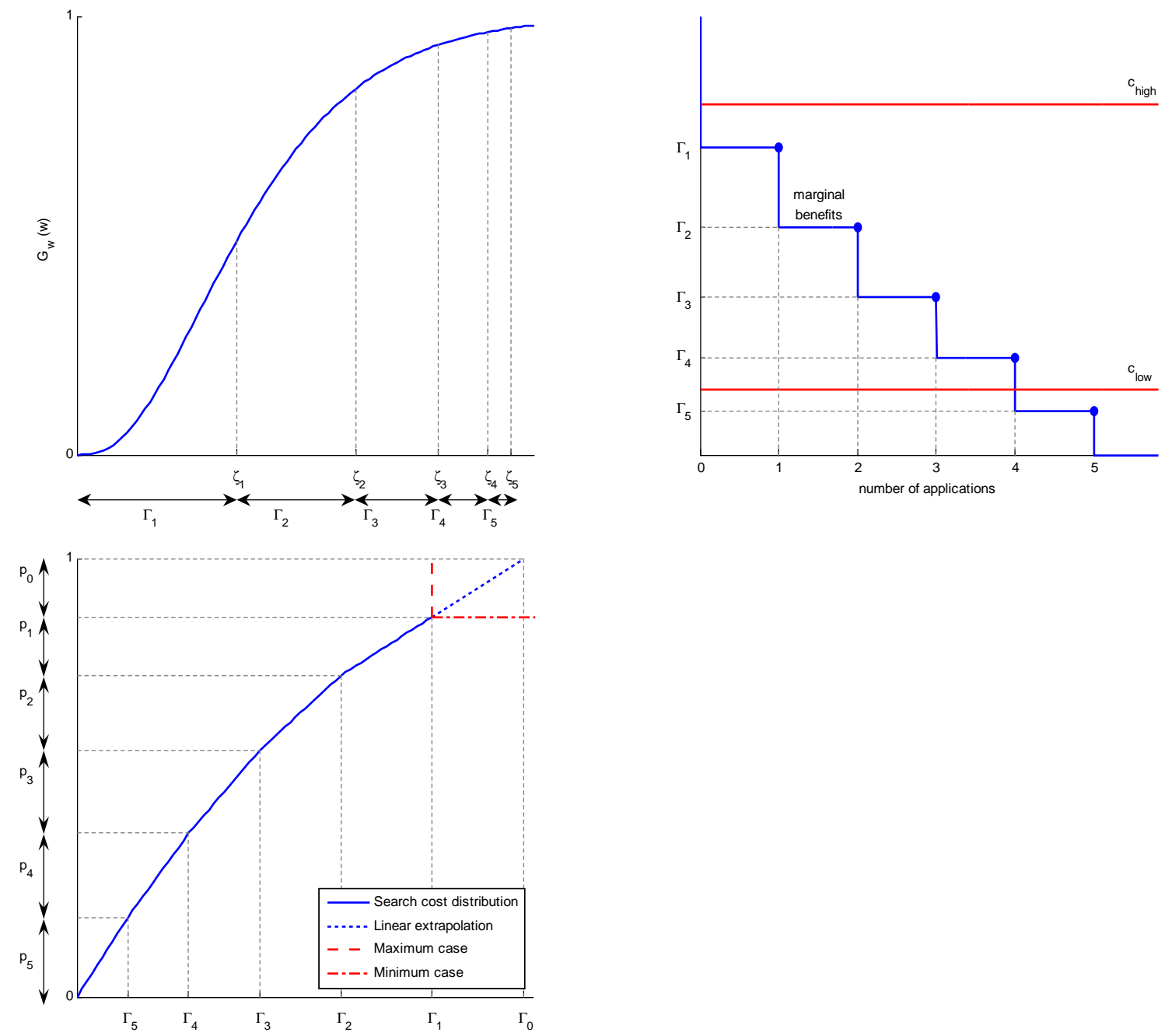

Figure 2: Relation between the wage distribution and the search cost distribution. For the ease of graphical exposition, the figure shows a special case in which $b=0, w_{R}=0, r+d=1$ and $S=5$. The figure should be interpreted as an illustration, not as a correct description of the actual distributions of wages and search costs. 

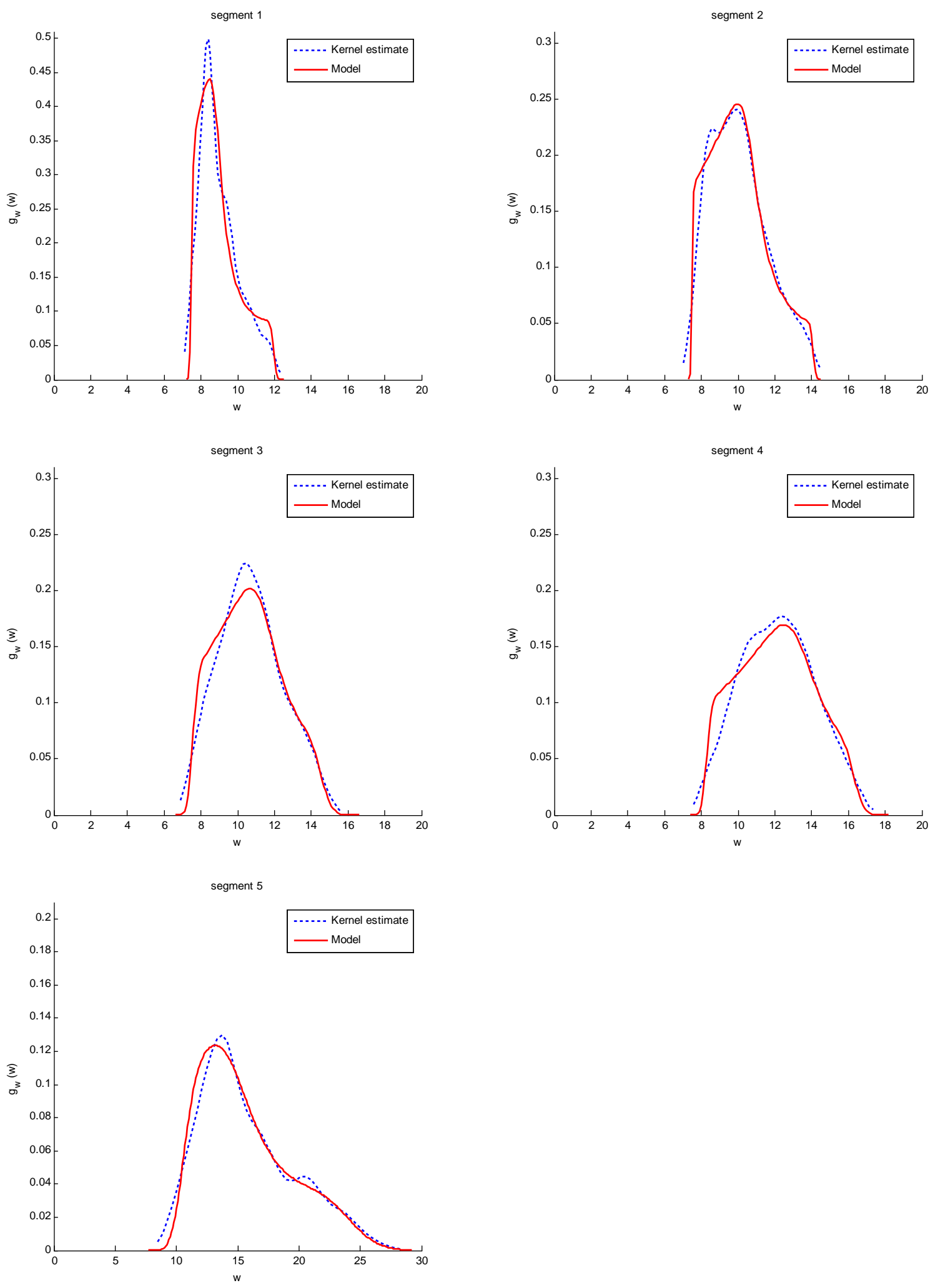

Figure 3: Estimated wage densities 

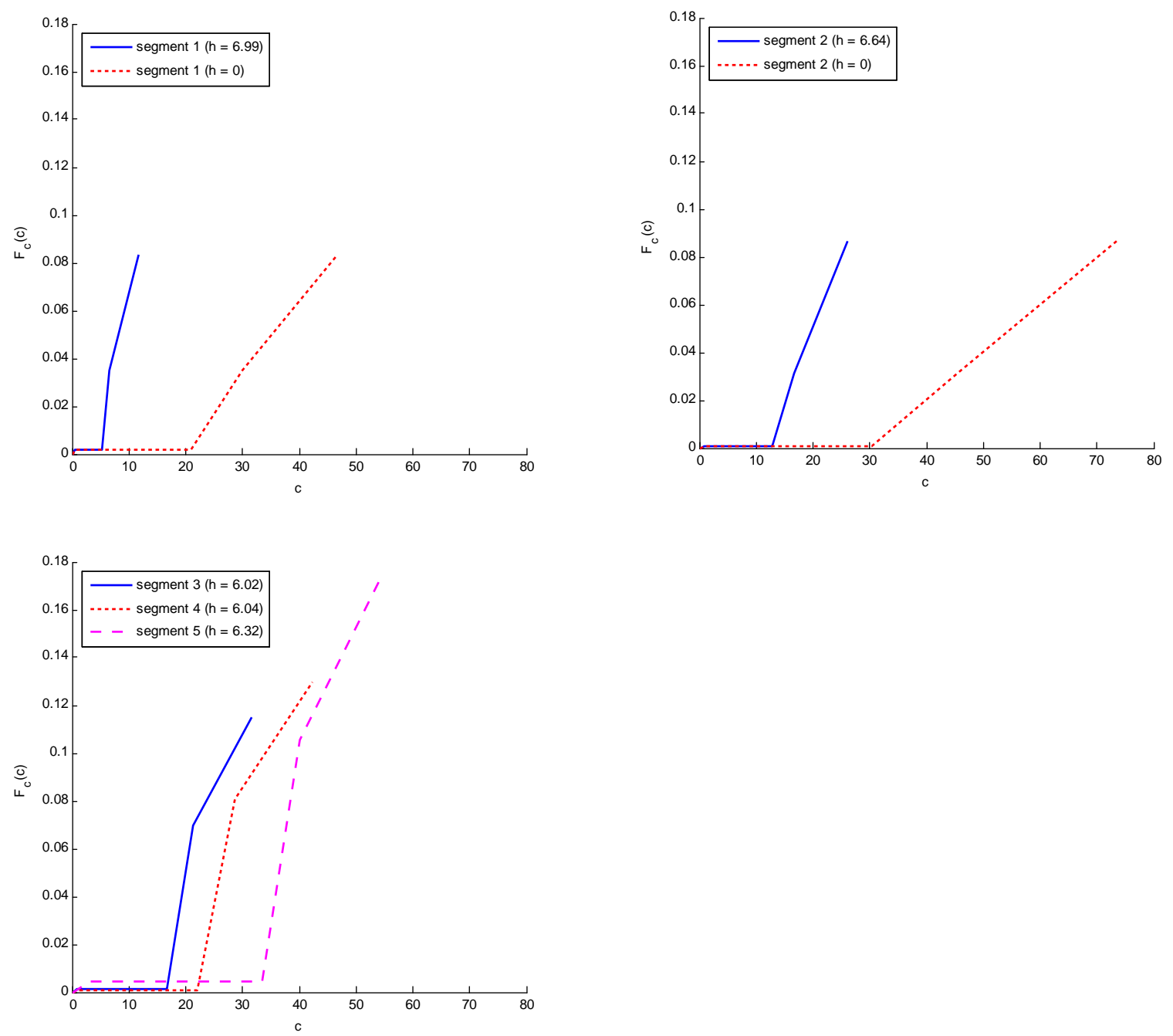

Figure 4: Estimated search cost distributions 

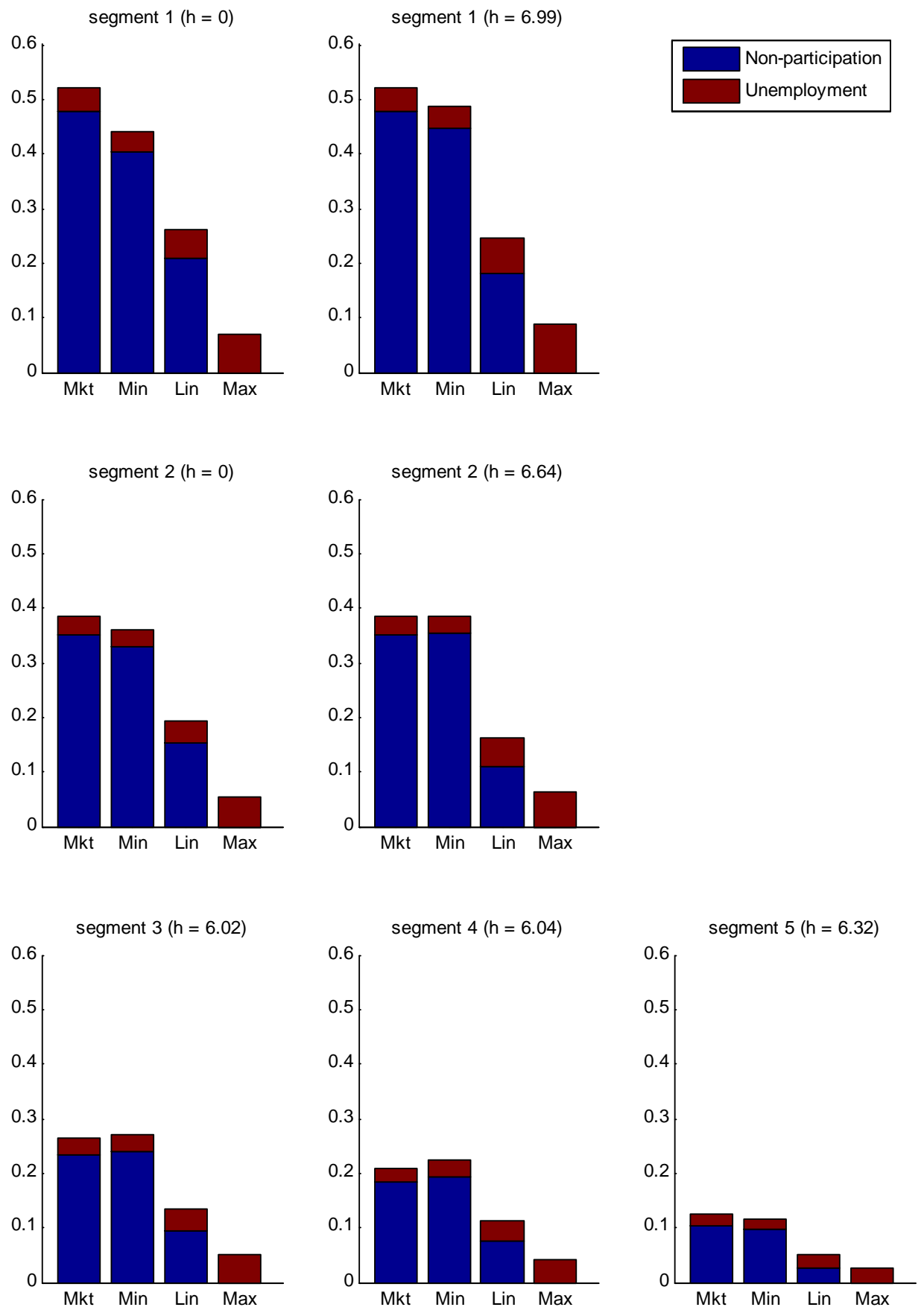

Figure 5: Non-participation and unemployment for each segment in the market equilibrium (mkt) and the planner's solutions (min, lin, and max). 